\title{
Synthesis, preclinical evaluation, and a pilot clinical PET imaging study of ${ }^{68} \mathrm{Ga}-$ labeled FAPI dimer
}

Authors: Liang Zhao ${ }^{1,2 *}$, Bo Niu ${ }^{3 *}$, Jianyang Fang ${ }^{4 *}$, Yizhen Pang ${ }^{1}$, Siyang $\mathrm{Li}^{3}$, Chengrong $\mathrm{Xie}^{5}$, Long Sun ${ }^{1}$, Xianzhong Zhang ${ }^{4}$, Zhide Guo ${ }^{4} \dagger$, Qin $\operatorname{Lin}^{2} \dagger$, and Haojun Chen ${ }^{1} \dagger$

1 Department of Nuclear Medicine \& Minnan PET Center, The First Affiliated Hospital of Xiamen University, Xiamen, China

2 Department of Radiation Oncology, The First Affiliated Hospital of Xiamen University, Xiamen, China;

${ }^{3}$ School of medicine, Xiamen University, Xiamen, China;

${ }^{4}$ State Key Laboratory of Molecular Vaccinology and Molecular Diagnostics \& Center for Molecular Imaging and Translational Medicine, School of Public Health, Xiamen University, Xiamen, China;

${ }^{5}$ Fujian Provincial Key Laboratory of Chronic Liver Disease and Hepatocellular Carcinoma, Xiamen, China;

* First authors, contributed equally to this work

Liang Zhao, Email: wzhaoliang01@163.com

Bo Niu, Email: niubofrank@163.com

Jianyang Fang, Email: jianyangfang@foxmail.com 


\section{† Corresponding authors:}

Zhide Guo, PhD

School of Public Health, Xiamen University, China

Email: gzd666888@xmu.edu.cn

Qin Lin, MD, PhD

Department of Radiation Oncology, The First Affiliated Hospital of Xiamen University, Xiamen, China

Email: linqin05@163.com

Haojun Chen, MD, PhD

Department of Nuclear Medicine \& Minnan PET Center, The First Affiliated Hospital of Xiamen University, Xiamen, China

Email: leochen0821@foxmail.com

Tel: +86-592-2137077

ORCID ID: 0000-0002-9101-8884

Funding: This work was funded by the National Natural Science Foundation of China (Grant number 82071961,81901805 , and 81772893 ) and the key medical and health projects in Xiamen (Grant number 3502Z20191104).

Running title: Pilot study of ${ }^{68} \mathrm{Ga}$-labeled FAPI dimer

Immediate Open Access: Creative Commons Attribution 4.0 International License (CC BY) allows users to share and adapt with attribution, excluding materials credited to previous publications.

License: https://creativecommons.org/licenses/by/4.0/. Details: https://jnm.snmjournals.org/page/permissions.

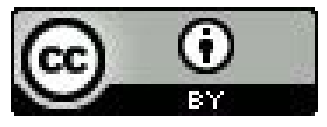




\section{ABSTRACT}

Cancer-associated fibroblasts (CAFs) are crucial components of the tumor microenvironment. Fibroblast activation protein (FAP) is overexpressed in CAFs. FAP-targeted molecular imaging agents, including FAP inhibitor (FAPI)-04 and FAPI-46, have shown promising results in tumor diagnosis. However, these molecules have relatively short tumor-retention time for peptide-targeted radionuclide therapy applications. We aimed to design a ${ }^{68} \mathrm{Ga}$-labeled FAPI dimer (denoted as ${ }^{68} \mathrm{Ga}-\mathrm{DOTA}-2 \mathrm{P}(\mathrm{FAPI})_{2}$ ) to optimize the pharmacokinetics and evaluate whether this form is more effective than its monomeric analogs. Methods: ${ }^{68} \mathrm{Ga}-\mathrm{DOTA}-2 \mathrm{P}(\mathrm{FAPI}) 2$ was synthesized based on the quinoline-based FAPI variants (FAPI-46), and its binding properties were assayed in CAFs. Preclinical pharmacokinetics was determined in FAP-positive patient-derived xenografts (PDXs) using small-animal PET and biodistribution experiments. The effective dosimetry of ${ }^{68} \mathrm{Ga}-\mathrm{DOTA}-2 \mathrm{P}(\mathrm{FAPI})_{2}$ was evaluated in three healthy volunteers, and PET/ CT imaging of ${ }^{68} \mathrm{Ga}-\mathrm{FAPI}-46$ and ${ }^{68} \mathrm{Ga}-\mathrm{DOTA}-2 \mathrm{P}(\mathrm{FAPI}) 2$ was performed in three cancer patients. Results: ${ }^{68} \mathrm{Ga}-\mathrm{DOTA}-2 \mathrm{P}(\mathrm{FAPI}) 2$ was stable in phosphate-buffered saline and fetal bovine serum for $4 \mathrm{~h}$. The FAPI dimer showed high affinity and specificity for FAP in-vitro and in-vivo. The tumor uptake of ${ }^{68} \mathrm{Ga}-\mathrm{DOTA}-2 \mathrm{P}(\mathrm{FAPI})_{2}$ was approximately two-fold stronger than that of 
${ }^{68} \mathrm{Ga}-\mathrm{FAPI}-46$ in PDXs, while the healthy organs showed low tracer uptake and fast body clearance. The effective dose of ${ }^{68} \mathrm{Ga}-\mathrm{DOTA}-2 \mathrm{P}(\mathrm{FAPI})_{2}$ was $1.19 \mathrm{E}-02$ mSv/MBq, calculated using OLINDA. Finally, PET/CT scans in three cancer patients revealed higher intratumoral uptake of ${ }^{68} \mathrm{Ga}-\mathrm{DOTA}-2 \mathrm{P}(\mathrm{FAPI})_{2}$ than that of ${ }^{68} \mathrm{Ga}-\mathrm{FAPI}-46$ in all tumor lesions (maximum standardized uptake value: 8.1-39.0 vs. 1.7-24.0, respectively; $P<0.001)$. Conclusion: ${ }^{68} \mathrm{Ga}-\mathrm{DOTA}-2 \mathrm{P}(\mathrm{FAPI})_{2}$ has increased tumor uptake and retention properties compared to ${ }^{68} \mathrm{Ga}-\mathrm{FAPI}-46$, and it could be a promising tracer for both diagnostic imaging and targeted therapy of malignant tumors with positive expression of FAP.

Keywords: fibroblast activation protein; cancer-associated fibroblasts; FAPI dimer; patient-derived xenografts; PET imaging 


\section{INTRODUCTION}

Cancer-associated fibroblasts (CAFs) are crucial components of the tumor microenvironment and can constitute over half of the mass in various tumors. According to previous reports, CAFs play important roles in tumor growth, immune suppression, and cancer invasion $(1,2)$. Thus, CAFs may be promising targets for tumor diagnosis and therapy. Fibroblast activation protein (FAP) is overexpressed in the CAFs in numerous epithelial carcinomas and weakly expressed in healthy tissues; therefore, an attractive target for cancer research. The past few years have witnessed the expansion of research on FAP-targeted molecular imaging in tumor diagnosis (3-5).

Recently, there has been a growing application of FAP targeting, from diagnostic imaging to peptide-targeted radionuclide therapy (PTRT) (6-10). However, the reports on PTRT are mainly based on the FAP-inhibitor (FAPI)-04 and FAPI-46 peptides, which showed a relatively short tumor-retention time in preclinical models and human subjects (10-12). Another FAPI variant, FAP-2286, has been studied in PTRT to improve tumor-retention time (13). Moreover, mouse models used to evaluate the pharmacokinetics of FAPI variants were cancer cell-derived xenografts (CDXs) in previous research $(7,10,11)$. When xenotransplanted, CDXs adequately recruit mouse fibroblasts during tumor 
growth; thus, they are highly suitable for direct tracer comparisons (14). However, patient-derived xenografts (PDXs), established by direct implantation of fresh surgical tissue fragments into immunodeficient mice, could be more attractive because they retain the tumor environment and molecular signatures of the corresponding parental tumor compared to that of CDXs (15). However, the potential of PDXs for PET imaging of CAFs has been rarely investigated.

The polyvalency effect has been applied to develop multimeric peptides to enhance the tumor-targeting efficacy of the tracers and improve the quality of in-vivo imaging $(16,17)$. Moreover, adding an amphiphilic polyethylene glycol linker (PEGylation) has been widely used to improve the in-vivo kinetics of various pharmaceuticals $(16,18)$. In the present study, we designed and synthesized a novel FAPI dimer with two mini-PEG spacers (11-amino-3,6,9-trioxaundecanoic acid, with three ethylene oxide units) between the two FAPI motifs in the homodimeric peptides, denoted as DOTA-2P(FAPI)2. The novel dimeric FAP-targeted molecule was labeled with positron-emitting radionuclide ${ }^{68} \mathrm{Ga}\left({ }^{68} \mathrm{Ga}-\mathrm{DOTA}-2 \mathrm{P}(\mathrm{FAPI}) 2\right)$ for $\mathrm{PET}$ imaging. We present the results of ${ }^{68} \mathrm{Ga}-\mathrm{DOTA}-2 \mathrm{P}(\mathrm{FAPI})_{2}$ testing in PDX models, healthy volunteers, and cancer patients. We hypothesized that the dimeric FAPI is more effective than monomeric analogs in terms of tumor uptake and tumor-retention time. 


\section{MATERIALS AND METHODS}

\section{Chemistry and Radiochemistry}

The vender information of chemicals, cells, reagents, synthesis procedure, HPLC, liquid chromatography-mass spectrometry, and flow diagram of DOTA-2P(FAPI)2 are provided in the Supplemental material and Supplemental Fig. 1.

Radiolabeling of FAPI variants was performed by adjusting a mixture of $50 \mu \mathrm{g}$ (56.4 nmol) FAPI-46 or $50 \mu \mathrm{g}(25.3 \mathrm{nmol})$ DOTA-2P(FAPI)2, and $4 \mathrm{~mL}{ }^{68} \mathrm{Ga}$ solution (1.3 GBq in $0.6 \mathrm{M} \mathrm{HCl}$ ) to $\mathrm{pH}$ 3.3-3.6 with $1 \mathrm{~mL}$ sodium acetate $(2.5 \mathrm{M}$ in water; total volume of reaction: $5 \mathrm{~mL}$ ). After heating to $100^{\circ} \mathrm{C}$ for $15 \mathrm{~min}$, the product was isolated by a C18 Sep-Pak cartridge (WAT020515, Waters) using ethanol $(0.5 \mathrm{~mL})$ as the eluent. Quality control of radiosynthesis was performed using ultraviolet and radio-HPLC (details presented in Supplemental material).

The radiolabeled compound was incubated in phosphate-buffered saline (PBS) and fetal bovine serum (FBS) at $37^{\circ} \mathrm{C}$ for 1,2 , and $4 \mathrm{~h}$ to measure the in-vitro stability. Then, $0.5 \mathrm{~mL}$ of acetonitrile was added to remove plasma proteins from the serum after the sample was centrifuged at 1,2 , and $4 \mathrm{~h}$. Finally, the radiochemical purities were analyzed using radio-HPLC. 


\section{PDX Models Establishment}

Written informed consent was obtained from all patients, and the research protocol was approved by the Clinical Research Ethics Committee of the First Affiliated Hospital of Xiamen University (ID KYZ-2017-001). All animal care and experimental procedure were reviewed and approved by the Animal Care and Use Committee of the Xiamen University Laboratory Animal Center (ID XMULAC20170063). The establishment of PDX models was based on our previous protocols detailed in the Supplemental material (19).

\section{Western Blot and Histopathological Staining}

Western blot analysis was performed in CAFs and Huh7 cell line to select cells expressing FAP. CAFs or Huh7 cells were cultured in the RPMI 1640 or DMEM medium containing $10 \% \mathrm{FBS}$ at $37^{\circ} \mathrm{C}$ in $5 \% \mathrm{CO}_{2}$. Western blotting and histopathological staining were performed as described in the Supplemental Material according to our previous protocol (20).

\section{Radioligand Binding Studies}

Radioligand binding studies included cell uptake, cell uptake blocking, and FAP binding assay. CAFs expressing FAP were seeded in 24-well plates with 1640 
medium containing $10 \%$ FBS and cultivated for $48 \mathrm{~h}$ to a density of approximately $80 \%$ before the experiments. The medium was replaced with 1640 medium without FBS. ${ }^{68} \mathrm{Ga}-\mathrm{DOTA}-2 \mathrm{P}(\mathrm{FAPI}) 2$ or ${ }^{68} \mathrm{Ga}-\mathrm{FAPI}-46$ or ${ }^{68} \mathrm{Ga}-\mathrm{DOTA}-2 \mathrm{P}(\mathrm{FAPI})_{2}$ with $11.3 \mathrm{nmol}$ unlabeled FAPI-46 (for the blocking experiment) was added to the 24-well plates and incubated for the scheduled times $(10,30,60,90$, and 120 min). The FAP-binding assays were performed by simultaneous exposure to unlabeled FAPI variants $\left(1.27 \times 10^{-4} \text { to } 10^{-13} \mathrm{M} \text { for }{ }^{68} \mathrm{Ga} \text {-DOTA-2P(FAPI }\right)_{2} ; 2.83 \times$ $10^{-4}$ to $10^{-13} \mathrm{M}$ for ${ }^{68} \mathrm{Ga}-\mathrm{FAPI}-46$ ) and radiolabeled compounds for $60 \mathrm{~min}$. The inhibitory concentration of $50 \%\left(\mathrm{IC}_{50} \mathrm{~S}\right)$ was calculated by fitting the data by nonlinear regression using GraphPad Prism. In each step of the experiments, the cells were washed twice with $1 \mathrm{~mL}$ of PBS. Finally, CAFs were lysed with $0.5 \mathrm{~mL}$ of $1 \mathrm{M} \mathrm{NaOH}$ for radioactivity counting (counts per minute, $\mathrm{cpm}$ ), examined in a $\mathrm{Y}$-counter. Each independent experiment was repeated three times.

\section{PET Imaging and Biodistribution Study in HCC-PDXs Models}

The products of ${ }^{68} \mathrm{Ga}-\mathrm{DOTA}-2 \mathrm{P}(\mathrm{FAPI}) 2$ and ${ }^{68} \mathrm{Ga}-\mathrm{FAPI}-46$ were diluted to the concentration of $74 \mathrm{MBq} / \mathrm{mL} .7 .4 \mathrm{MBq}$ (bout $0.1 \mathrm{~mL}$ ) of ${ }^{68} \mathrm{Ga}-\mathrm{DOTA}-2 \mathrm{P}(\mathrm{FAPI})_{2}$ or ${ }^{68} \mathrm{Ga}-\mathrm{FAPI}-46$ were intravenously injected into HCC-PDXs ( $\mathrm{n}=3$ for each group). All PET scans were conducted using an Inveon small-animal PET scanner 
(Siemens Preclinical Solution). Dynamic and static PET imaging procedures are provided in the Supplemental material.

In the biodistribution study, the products of ${ }^{68} \mathrm{Ga}-\mathrm{DOTA}-2 \mathrm{P}(\mathrm{FAPI})_{2}$ and ${ }^{68} \mathrm{Ga}-\mathrm{FAPI}-46$ were diluted to the concentration of $14.8 \mathrm{MBq} / \mathrm{mL}$. HCC-PDX mice were injected with the same batch of $1.48 \mathrm{MBq}{ }^{68} \mathrm{Ga}-\mathrm{DOTA}-2 \mathrm{P}(\mathrm{FAPI})_{2}$ and sacrificed at different times ( 1 and 4 h p.i.; $\mathrm{n}=3$ for each time point). The main organs and tumors were isolated, weighed, and analyzed. The biodistribution in the ${ }^{68} \mathrm{Ga}-\mathrm{FAPI}-46$ group (1.48 MBq) and the blocking group $\left({ }^{68} \mathrm{Ga}-\mathrm{DOTA}-2 \mathrm{P}(\mathrm{FAPI})_{2}[1.48 \mathrm{MBq}]\right.$ with $30 \mathrm{nmol}$ of unlabeled FAPI-46) was also evaluated for comparison. The radioactivity (counts per minute, $\mathrm{cpm}$ ) was measured with a $\mathrm{y}$-counter.

\section{PET Imaging in Healthy Volunteers and Cancer Patients}

The clinical study was registered at ClinicalTrials.gov (NCT04941872). The Clinical Research Ethics Committee of the First Affiliated Hospital of Xiamen University approved this study and all subjects signed a written informed consent. Safety data were collected before and $4 \mathrm{~h}$ after injection of ${ }^{68} \mathrm{Ga}-\mathrm{DOTA}-2 \mathrm{P}(\mathrm{FAPI}) 2$, including vital signs (blood pressure, heart rate, respiratory frequency, and temperature) and adverse events. The scan and reconstruction procedures are presented in the Supplemental material according to a previously described 
protocol (21). Time-activity curve fitting and subsequent dose calculations were performed using OLINDA/EXM v.1.1 (22).

\section{Statistical Analysis}

All quantitative data are expressed as mean $\pm \mathrm{SD}$. All statistical analyses were conducted using SPSS 22.0, a statistical analysis software (IBM). One-way analysis of variance, Student's $t$-test, and Wilcoxon matched-pairs signed-rank test were used to compare means. Statistical significance was set at $P<0.05$.

\section{RESULTS}

\section{Synthesis and Radiolabeling}

The dimer of FAPI-46 with two $\mathrm{PEG}_{3}$ groups and the chelator DOTA was synthesized (Fig. 1 and Supplemental Fig. 1). Subsequently, two radioligands were prepared as controls and tests: ${ }^{68} \mathrm{Ga}-\mathrm{FAPI}-46$, first reported by Loktev A et al. (3), and ${ }^{68} \mathrm{Ga}-\mathrm{DOTA}-2 \mathrm{P}(\mathrm{FAPI}) 2$, the dimer of FAPI-46. ${ }^{68} \mathrm{Ga}-\mathrm{DOTA}-2 \mathrm{P}(\mathrm{FAPI}) 2$ and ${ }^{68} \mathrm{Ga}-\mathrm{FAPI}-46$ were radiolabeled at an average specific activity of 37 and 16.5 $\mathrm{GBq} / \mu \mathrm{mol}$, respectively, with $>95 \%$ radiochemical purity after purification (Supplemental Fig. 2A-B).

The stability of ${ }^{68} \mathrm{Ga}-\mathrm{DOTA}-2 \mathrm{P}(\mathrm{FAPI})_{2}$ was evaluated in PBS and FBS 1, 2, and $4 \mathrm{~h}$ after incubation. HPLC analysis results showed that 
${ }^{68} \mathrm{Ga}-\mathrm{DOTA}-2 \mathrm{P}(\mathrm{FAPI}) 2$ had high stability for up to $4 \mathrm{~h}$ with no significant demetalation observed in either PBS (92.78\%) or FBS (97.80\%) (Supplemental Fig. 2C-D).

\section{Cell-based Experiments}

The binding properties of FAPI variants were first verified and evaluated in a FAP-expressing cell line. Western blotting results revealed that FAP was highly expressed in CAFs, and negatively expressed in Huh7 cells (Fig. 2A). Since FAP is expressed on the CAFs surface, ${ }^{68} \mathrm{Ga}-\mathrm{DOTA}-2 \mathrm{P}(\mathrm{FAPI})_{2}$ and ${ }^{68} \mathrm{Ga}-\mathrm{FAPI}-46$ could bind to FAP rapidly. The uptake of ${ }^{68} \mathrm{Ga}-\mathrm{FAPI}-46$ reached approximately $1.5 \%$ after 10 min of incubation and then slightly increased until $120 \mathrm{~min}$. The uptake pattern of ${ }^{68} \mathrm{Ga}$-DOTA-2P(FAPI)2 was similar; however, the uptake value was approximately double. Regarding the cell uptake-blocking experiment, the FAPI-46 precursor could significantly block the binding between ${ }^{68} \mathrm{Ga}-\mathrm{DOTA}-2 \mathrm{P}(\mathrm{FAPI}) 2$ and FAP (Fig. 2B). The mean value $\pm \mathrm{SD}$ and error of the IC 50 values for the monomer were $2.06 \pm 1.84 \mathrm{nM}$ and $1.06 \mathrm{nM}$, respectively, and for the dimer were $3.68 \pm 1.82 \mathrm{nM}$ and $1.05 \mathrm{nM}$ (Fig. 2C-D). The comparable IC $\mathrm{C}_{50}$ values of DOTA-2P(FAPI $)_{2}$ and $\mathrm{FAPI}-46$ suggest that the dimerization of the FAPI structure has a minimal effect on the receptor-binding avidity. 


\section{HCC-PDXs Establishment and Validation}

Two different groups of HCC-PDXs were successfully established, denoted as HCC-PDX-1 and HCC-PDX-2. The two groups had different clinical data (Patient 1: male, T1aNOM0, poorly differentiated HCC; Patient 2: male, T1bNOM0, moderately differentiated $\mathrm{HCC}$ ), both with high levels of FAP expression (Supplemental Fig. 3). Both groups showed histopathological characteristics (FAP, Ki67, and H\&E; Supplemental Fig. 3) consistent with their corresponding primary HCC and were chosen as the experimental models to evaluate the in-vivo behavior of ${ }^{68} \mathrm{Ga}-\mathrm{DOTA}-2 \mathrm{P}(\mathrm{FAPI}) 2$.

\section{Small-animal PET Studies}

In HCC-PDX-1, both radiotracers were absorbed highly by the tumor at $0.5 \mathrm{~h}$ after injection, and the uptake decreased relatively slowly until $4 \mathrm{~h}$ (Figure 3). However, the tumor uptake of ${ }^{68} \mathrm{Ga}-\mathrm{DOTA}-2 \mathrm{P}(\mathrm{FAPI})_{2}$ was significantly higher than that of

${ }^{68} \mathrm{Ga}-\mathrm{FAPI}-46$. The detailed \%ID/g tumor values for both tracers from small-animal PET are shown in Supplemental Fig. 4A. Other organs demonstrated low non-specific binding that quickly decreased (Supplemental Fig. 4B-E), resulting in low background signal and favorable tumor-to-background 
ratios. For a comprehensive investigation of the early pharmacokinetics of ${ }^{68} \mathrm{Ga}-\mathrm{DOTA}-2 \mathrm{P}(\mathrm{FAPI}) 2,60-\mathrm{min}$ dynamic PET was performed in HCC-PDX-1. The tumor accumulation of ${ }^{68} \mathrm{Ga}-\mathrm{DOTA}-2 \mathrm{P}(\mathrm{FAPI})_{2}$ was rapid, and the time dependency of the FAPI-dimer uptake was similar to other FAPI tracers. In contrast, the heart, kidney, and liver uptake showed sharp elimination (Fig. 3). Regarding ${ }^{68} \mathrm{Ga}-\mathrm{DOTA}-2 \mathrm{P}(\mathrm{FAPI})_{2} \mathrm{PET}$ in HCC-PDX-2, the tumor accumulation was rapid. Slightly decreased tumor uptake was observed from $30 \mathrm{~min}$ to $1 \mathrm{~h}$, then it remained constant between 1 and $4 \mathrm{~h}$ (Fig. 4A and Supplemental Fig. 5), similarly to that in HCC-PDX-1. The 60-min dynamic PET was also performed in HCC-PDX-2 (Supplemental Fig. 6).

Target specificity was evaluated by simultaneous administration of unlabeled FAPI-46 as a competitor with ${ }^{68} \mathrm{Ga}-\mathrm{DOTA}-2 \mathrm{P}(\mathrm{FAPI}) 2$. The tumor uptake $1 \mathrm{~h}$ after injection was suppressed greatly by blocking in HCC-PDX-1 and HCC-PDX-2, and the radiotracer clearance in most organs was faster than that without blocking (Fig. 4B). The uptake values of the tumor and key organ with or without competitor are presented in Supplemental Figures 4F and 5F.

\section{Organ Distribution in HCC-PDX-1}


The biodistribution of ${ }^{68} \mathrm{Ga}-\mathrm{FAPI}-46$ in HCC-PDX-1 was determined by ex-vivo counting in tissues collected 1 and $4 \mathrm{~h}$ after injection (Fig. 5A). At $1 \mathrm{~h}$ p.i., ${ }^{68} \mathrm{Ga}-\mathrm{FAPI}-46$ accumulated mainly in the tumor $(4.60 \pm 1.12 \% \mathrm{ID} / \mathrm{g})$ and kidney $(4.42 \pm 0.97 \% \mathrm{ID} / \mathrm{g})$, and the tumor-to-kidney $(\mathrm{T} / \mathrm{K})$ ratio was $1.05 \pm 0.18$. Four hours p.i., ${ }^{68} \mathrm{Ga}-\mathrm{FAPI}-46$ in the blood, heart, liver, lung, and spleen decreased sharply, whereas the tumor uptake was steady $(3.81 \pm 0.18 \% \mathrm{ID} / \mathrm{g})$. The biodistribution of ${ }^{68} \mathrm{Ga}-\mathrm{DOTA}-2 \mathrm{P}(\mathrm{FAPI})_{2}$ was also assessed in the same PDX model by comparison (Figure 5B). Consistently with the PET findings, ${ }^{68} \mathrm{Ga}-\mathrm{DOTA}-2 \mathrm{P}(\mathrm{FAPI}) 2$ demonstrated higher uptake in the tumor than ${ }^{68}$ Ga-FAPI-46, 1 h p.i. $(8.97 \pm 0.32$ vs. $4.60 \pm 1.12 \% \mathrm{ID} / \mathrm{g}, P=0.003)$ and $4 \mathrm{~h}$ p.i. (7.61 \pm 0.64 vs. $3.81 \pm 0.18 \% \mathrm{ID} / \mathrm{g}, P=0.001)$. The organ uptake of ${ }^{68} \mathrm{Ga}-\mathrm{DOTA}-2 \mathrm{P}(\mathrm{FAPI}) 2$ was slightly greater than that of ${ }^{68} \mathrm{Ga}-\mathrm{FAPI}-46$ both 1 and $4 \mathrm{~h}$ p.i. As a result, ${ }^{68} \mathrm{Ga}-\mathrm{DOTA}-2 \mathrm{P}(\mathrm{FAPI}) 2$ had a higher $\mathrm{T} / \mathrm{K}$ ratio than ${ }^{68} \mathrm{Ga}-\mathrm{FAPI}-46(\mathrm{~T} / \mathrm{K}: 1.60 \pm 0.26$ vs $1.05 \pm 0.18, P=0.039,1 \mathrm{~h}$ p.i.), although the difference was not significant 4 h p.i. $(1.33 \pm 0.29$ vs $0.95 \pm 0.09, P=0.093)$.

Regarding the blocking group, a dramatic decrease of radioactivity was detected in most organs (Fig. 5B), and the tumor uptake decreased most significant (8.97 \pm 0.32 vs. $1.07 \pm 0.19 \%$ ID/g 1 h p.i., $P<0.001$, Student's t-test; $7.61 \pm 0.64$ vs. $1.14 \pm 0.15 \%$ ID/g 4 h p.i., $P=0.002$, Student's t-test). 
Additional biodistribution and PET studies were performed to rule out the effect of molar activity on comparative experiments between FAPI dimer and FAPI-46. The amount of precursor administered was $23 \mu \mathrm{g}(25.9 \mathrm{nmol})$ for FAPI-46 and $50 \mu \mathrm{g}(25.3 \mathrm{nmol})$ for DOTA-2P(FAPI)2, resulting in the same specific activity for ${ }^{68} \mathrm{Ga}-\mathrm{FAPI}-46$ and ${ }^{68} \mathrm{Ga}-\mathrm{FAPI}-$ dimer. Under these circumstances, the results from the biodistribution study demonstrated that

${ }^{68} \mathrm{Ga}-\mathrm{FAPI}$-dimer had higher tumor uptake than ${ }^{68} \mathrm{Ga}-\mathrm{FAPI}-46(8.45 \pm 2.19$ vs. $4.03 \pm 0.69 \% \mathrm{ID} / \mathrm{g} ; P=0.029$, Student's t-test, Supplemental Fig. 7). Similar results were observed from the PET imaging study (Supplemental Fig. 8).

\section{Adverse Events}

All observed vital signs (including blood pressure, heart rate, and body temperature) remained normal during the injection and at 4-h follow-up. No individuals reported any adverse events.

\section{Dosimetry Estimate}

The dosimetry reports and a representative figure for three healthy volunteers are shown in Table 1 and Fig. 6. There was no time dependency of tracer uptake, showing that the tracer distribution was not obviously changing after $10 \mathrm{~min}$. The 
effective dose of ${ }^{68} \mathrm{Ga}-\mathrm{DOTA}-2 \mathrm{P}(\mathrm{FAPI}) 2$ was $1.19 \mathrm{E}-02 \mathrm{mSv} / \mathrm{MBq}$, calculated using OLINDA. The organ with the highest effective dose was the thyroid (3.11E-03 mSv/MBq), followed by the liver (1.65E-03 mSv/MBq) and lungs (1.36E-03 mSv/MBq). Overall, the effective dose of ${ }^{68} \mathrm{Ga}-\mathrm{DOTA}-2 \mathrm{P}(\mathrm{FAPI})_{2}$ was comparable with those of ${ }^{68} \mathrm{Ga}-\mathrm{FAPI}-02(1.80 \mathrm{E}-02 \mathrm{mSv} / \mathrm{MBq})$ and ${ }^{68} \mathrm{Ga}-\mathrm{FAPI}-04$ (1.64E-02 mSv/MBq) (4), and higher than ${ }^{68} \mathrm{Ga}-\mathrm{FAPI}-46$ (7.80E-03 mSv/MBq) (23).

\section{${ }^{68} \mathrm{Ga}-\mathrm{DOTA}-2 \mathrm{P}(\mathrm{FAPI})_{2} \mathrm{PET}$ Imaging in Cancer Patients}

${ }^{68} \mathrm{Ga}-\mathrm{FAPI}-46$ and ${ }^{68} \mathrm{Ga}-\mathrm{DOTA}-2 \mathrm{P}(\mathrm{FAPI}) 2 \mathrm{PET} / \mathrm{CT}$ scans were performed after 60 min of intravenous administration in three patients: one with nasopharyngeal non-keratinized undifferentiated carcinoma, wild diffuse bone metastases after chemoradiotherapy and immunotherapy; one with papillary thyroid carcinoma, wild diffuse lymph node metastases after total thyroidectomy and multiple cycles of radioiodine treatment; and one with HCC, treatment-naïve. Representative PET images of these three patients after administration of ${ }^{68} \mathrm{Ga}-\mathrm{FAPI}-46$ and ${ }^{68} \mathrm{Ga}-\mathrm{DOTA}-2 \mathrm{P}(\mathrm{FAPI})_{2}$ are shown in Fig. 7 and Supplemental Fig. 9 and 10. In the patient with metastatic thyroid cancer, ${ }^{68} \mathrm{Ga}-\mathrm{DOTA}-2 \mathrm{P}(\mathrm{FAPI}) 2$ was mainly accumulated in the tumor, pancreas, submandibular glands, and blood pool. Interestingly, the activity of FAPI dimer in the blood pool remained at a high level 
(maximum standardized uptake value, SUVmax 8.3) $4 \mathrm{~h}$ p.i. All tumor lesions were clearly visible owing to the favorable tumor-to-background ratios. In the lesion-to-lesion comparison, the dimer uptake in 21 lesions (from 3 patients) was higher than monomer uptake (SUVmax $1 \mathrm{~h}$ p.i.: 8.1-39.0 vs. 1.7-24.0, respectively; $P<0.001$ by Wilcoxon matched-pairs signed-rank test, mean SUVmax: 15.3 vs. 23.9; Supplemental Table 1). In addition, the ${ }^{68} \mathrm{Ga}-2 \mathrm{P}(\mathrm{FAPI}) 2$ uptake in tumors was slightly decreased from 1 to $4 \mathrm{~h}$ (SUVmax 1 h p.i.: 8.1-39.0; 4 h p.i.: 6.6-35.0).

\section{DISCUSSION}

With a burst of preclinical and clinical research on quinoline-based FAPI variants, two main hurdles remain: improving the tumor retention time and finding the appropriate preclinical models. Since FAP is mainly overexpressed in CAFs and not in tumor cells, the tumor cell-line transfected with human or murine FAP could not reflect the tumor microenvironment $(3,7)$. In contrast, PDXs can reliably reproduce a patient's parental tumor for histopathology and genetics (15). Therefore, PDXs are suitable models for studying tumor biology, including the microenvironment and patient sensitivity to target agents. Despite an increasing number of case studies (6-9) and two clinical trials with a small patient population $(13,24)$ for FAP-based PTRT, basic research on this topic is rare $(10)$. In the present study, PDXs derived from HCC could maintain the principal 
histopathological characterization of the human tumor, confirming the robustness of this model for testing the properties of the new FAPI variant.

As a pan-cancer target, labelling FAPI monomers with different imaging isotopes has shown impressive results in several tumor diagnoses $(3-5,25)$; however, the pharmacokinetics with fast clearance from blood and short retention in tumors are problematic issues for PTRT application. Thus, structural modification of FAPI for optimizing tumor uptake and tumor retention time for PTRT is another key research direction.

Based on the polyvalent effect, multimeric peptides can help improve tumor-targeting efficacy and generate higher quality in-vivo imaging. This strategy has been widely used in the development of multimeric Arg-Gly-Asp (RGD) peptides $(16,17)$. Indeed, given the distance between two FAPI motifs in DOTA-2P(FAPI) 2 may not be long enough, it is unlikely that they would bind to two adjacent FAP sites simultaneously. However, the binding of one FAPI motif to FAP will significantly increase the local concentration of a second FAP motif in the vicinity of FAP sites. The locally enhanced FAPI concentration may explain the higher tumor uptake of radiolabeled FAPI dimers compared to their monomeric analogs. Similar findings were observed in the studies of radiolabeled RGD-dimers (26). Nonetheless, it should be noted that although tetrameric and 
octameric peptides possess higher receptor-binding affinity and higher tumor uptake than their dimeric and monomeric counterparts, they also have substantially higher background activity, especially in the kidney (27). Therefore, dimeric peptides seem to be an optimal choice owing to their increased tumor uptake and favorable pharmacokinetics (27). PEGylation is another widely used strategy to improve the in-vivo pharmacokinetics of radiotracers. According to previous reports where PEGylated RGD peptides were labeled with different isotopes, PEGylation improved the labeling yield and in-vivo pharmacokinetics $(16,18)$. However, PEGylation also induces hydrophilicity and increases kidney uptake, partially explaining the high initial kidney uptake compared to other FAPI derivatives. In this study, we designed and synthesized a novel FAPI dimer with two mini-PEG spacers between the FAPI motifs in homodimeric peptides. The in-vitro binding assays demonstrated that DOTA-2P(FAPI $)_{2}$ had specific and high binding affinity to FAP expressed on CAFs, revealing that the polyvalent strategy did not compromise its FAP-binding affinity.

After radiolabeling with ${ }^{68} \mathrm{Ga}$, the FAPI dimers exhibited improved in-vivo pharmacokinetics and enhanced tumor uptake compared to the FAPI monomer. Dynamic PET scans in the two HCC-PDX groups showed prominent tumor uptake and predominant organ clearance. After applying the tracers to static PET scans, 
${ }^{68} \mathrm{Ga}-\mathrm{DOTA}-2 \mathrm{P}(\mathrm{FAPI}) 2$ demonstrated higher tumor uptake than ${ }^{68} \mathrm{Ga}-\mathrm{FAPI}-46$ at all time points examined in both PDXs. In the small-animal PET imaging study, higher initial (30 min p.i.) kidney and liver uptake for ${ }^{68} \mathrm{Ga}-\mathrm{DOTA}-2 \mathrm{P}(\mathrm{FAPI})_{2}$ was observed compared to FAPI-monomers, including ${ }^{68} \mathrm{Ga}-\mathrm{FAPI}-04,{ }^{68} \mathrm{Ga}-\mathrm{FAPI}-46$, and ${ }^{18} \mathrm{~F}$-FGlc-FAPI (14). However, the kidney and liver uptake were quickly eliminated at 60 min p.i. in PET imaging and the biodistribution study. The high initial kidney uptake and rapid renal clearance may be attributed to the insertion of two PEG groups, which improved the hydrophilic properties $(16,18)$. Nevertheless, the main organs uptake should be carefully estimated for safety dose limitation when FAPI dimer is labeled with ${ }^{177} \mathrm{Lu}$ for targeted radionuclide therapy. The FAP specificity of ${ }^{68} \mathrm{Ga}$-DOTA-2P(FAPI $)_{2}$ was strongly confirmed by effective uptake inhibition in the presence of unlabeled FAPI-46 in cell-uptake, PET scan, and biodistribution experiments.

It was reported that the FAP-blocking dose (cold mass of FAPI) in one mouse was $30 \mathrm{nmol}(7,11)$. Since the specific activity of FAPI dimer and FAPI-46 was 37 $\mathrm{GBq} / \mu \mathrm{mol}$ and $16.5 \mathrm{GBq} / \mu \mathrm{mol}$, respectively, in this study, a dose of $7.4 \mathrm{MBq}$ ${ }^{68} \mathrm{Ga}-\mathrm{FAPI}-46\left(0.45 \mathrm{nmol}\right.$, hot and cold mass) or ${ }^{68} \mathrm{Ga}-\mathrm{FAPI}-$ dimer $(0.2 \mathrm{nmol}$, hot and cold mass) per mouse for PET imaging may have minimal impact on the tumor uptake. Therefore, there is no effect of the different injected cold mass of 
the radiotracers that might have caused the significant differences in tumor uptake values. Moreover, additional PET imaging and biodistribution experiments have been performed to rule out the effect of molar activity on all comparative experiments of dimeric and monomeric inhibitors.

The encouraging results of the in-vitro and mouse studies led to the clinical translation of FAPI dimer into human subjects. The radiation dose deposition of ${ }^{68} \mathrm{Ga}-\mathrm{DOTA}-2 \mathrm{P}(\mathrm{FAPI})_{2}$ in healthy organs was estimated using the PET data of three healthy volunteers at four time points. The average effective whole-body dose was $1.19 \mathrm{E}-02 \mathrm{mSv} / \mathrm{MBq}$. This estimate is comparable with the previously reported effective doses of those of ${ }^{68} \mathrm{Ga}-\mathrm{FAPI}-02$ and ${ }^{68} \mathrm{Ga}-\mathrm{FAPI}-04$ (1.80E-02 and 1.64E-02 mSv/MBq), and higher than ${ }^{68} \mathrm{Ga}-\mathrm{FAPI}-46$ (7.80E-03 mSv/MBq) $(4,23)$.

Regarding the clinical diagnosis, ${ }^{68} \mathrm{Ga}-\mathrm{DOTA}-2 \mathrm{P}(\mathrm{FAPI})_{2} \mathrm{PET} / \mathrm{CT}$ imaging in the patients examined showed a rapid and stable accumulation of the dimer in tumorous lesions, consistently with the results of animal experiments. Tumor uptake in most lesions was significantly higher with ${ }^{68} \mathrm{Ga}-\mathrm{DOTA}-2 \mathrm{P}(\mathrm{FAPI}) 2$ than with ${ }^{68} \mathrm{Ga}-\mathrm{FAPI}-46$, leading to visualization of primary lesions and metastases more clearly. Interestingly, the retention of the tracer in the patient blood pool remained high $4 \mathrm{~h}$ p.i., in contrast with mice findings. The prolonged retention in 
the blood pool may make DOTA-2P(FAPI)2 an attractive tracer for PTRT applications. Although the PET/CT results were encouraging in patients, high physiological uptake in the thyroid and pancreas should be noted. Nevertheless, DOTA-2P(FAPI) 2 labeling with ${ }^{68} \mathrm{Ga}$ demonstrated favorable data in cells, mice, and patients. Future development, especially for anti-tumor therapeutic applications, labeling the ligand with therapeutic radionuclides such as ${ }^{177} \mathrm{Lu}$ and ${ }^{90} \mathrm{Y}$ should be considered to compare the FAPI dimer with the monomer.

\section{CONCLUSION}

${ }^{68} \mathrm{Ga}-\mathrm{DOTA}-2 \mathrm{P}(\mathrm{FAPI}) 2$ provides an improved tumor uptake and longer tumor-retention time compared with ${ }^{68} \mathrm{Ga}-\mathrm{FAPI}-46$, and it could be a promising tracer for both diagnostic imaging and targeted radionuclide therapy in malignant tumors with positive FAP expression. Further work to optimize the pharmacokinetics of DOTA-2P(FAPI) 2 and evaluate its anti-tumor efficacy after labeling with therapeutic isotopes should be envisaged.

\section{Disclosures:}


Funding: This work was funded by the National Natural Science Foundation of China (Grant number 82071961, 81901805,and 81772893), and the key medical and health projects in Xiamen (Grant number 3502Z20191104).

Conflicts of interest: None.

Acknowledgments: The authors gratefully acknowledge Dr. Dongyan Shen (The First Affiliated Hospital of Xiamen University, Xiamen University, China) for providing the CAFs. 


\section{KEY POINTS}

\section{QUESTION:}

How is it possible to optimize tumor uptake and retention of the fibroblast activation protein (FAP)-targeting molecular agents?

\section{PERTINENT FINDINGS:}

In a pilot clinical cancer imaging study, ${ }^{68} \mathrm{Ga}-\mathrm{DOTA}-2 \mathrm{P}(\mathrm{FAPI})_{2}$ was synthesized as a FAP-inhibitor dimer and tested for its pharmacokinetic properties. Its tumor uptake was higher than that of monomeric FAPIs in-vitro, in-vivo, and in cancer patients.

\section{IMPLICATIONS FOR PATIENT CARE:}

${ }^{68} \mathrm{Ga}-\mathrm{DOTA}-2 \mathrm{P}(\mathrm{FAPI})_{2}$ shows improved tumor uptake and retention properties. It could be a promising candidate tracer for both diagnostic imaging and targeted therapy of malignant tumors with positive FAP expression. 


\section{REFERENCES}

1. Gaggioli C, Hooper S, Hidalgo-Carcedo C, et al. Fibroblast-led collective invasion of carcinoma cells with differing roles for RhoGTPases in leading and following cells. Nat Cell Biol. 2007;9:1392-1400.

2. Lakins MA, Ghorani E, Munir H, Martins CP, Shields JD. Cancer-associated fibroblasts induce antigen-specific deletion of CD8 (+) T Cells to protect tumour cells. Nat Commun. 2018:9:948.

3. Loktev A, Lindner T, Burger EM, et al. Development of fibroblast activation protein-targeted radiotracers with improved tumor retention. J Nucl Med. 2019;60:1421-1429.

4. Giesel FL, Kratochwil C, Lindner T, et al. (68)Ga-FAPI PET/CT: biodistribution and preliminary dosimetry estimate of 2 DOTA-containing FAP-targeting agents in patients with various cancers. $J$ Nucl Med. 2019;60:386-392.

5. Chen H, Pang Y, Wu J, et al. Comparison of [(68)Ga]Ga-DOTA-FAPI-04 and [(18)F] FDG PET/CT for the diagnosis of primary and metastatic lesions in patients with various types of cancer. Eur J NuCl Med Mol Imaging. 2020;47:1820-1832.

6. Ballal S, Yadav MP, Kramer V, et al. A theranostic approach of [(68)Ga]Ga-DOTA.SA.FAPi PET/CT-guided [(177)Lu]Lu-DOTA.SA.FAPi radionuclide therapy in an end-stage breast cancer patient: new frontier in targeted radionuclide therapy. Eur J Nucl Med Mol Imaging. 2021;48:942-944.

7. Lindner T, Loktev A, Altmann A, et al. Development of quinoline-based theranostic ligands for the targeting of fibroblast activation protein. J Nucl Med. 2018;59:1415-1422.

8. Lindner T, Altmann A, Kramer S, et al. Design and development of (99m)Tc-labeled FAPI tracers for SPECT imaging and (188)Re therapy. J Nucl Med. 2020;61:1507-1513.

9. Kratochwil C, Giesel FL, Rathke H, et al. [(153)Sm]Samarium-labeled FAPI-46 radioligand therapy in a patient with lung metastases of a sarcoma. Eur J Nucl Med Mol Imaging. 2021;48:3011-3013.

10. Watabe T, Liu Y, Kaneda-Nakashima K, et al. Theranostics targeting fibroblast activation protein in the tumor stroma: (64)Cu- and (225)Ac-labeled FAPI-04 in pancreatic cancer xenograft mouse models. J Nucl Med. 2020;61:563-569.

11. Loktev A, Lindner T, Mier W, et al. A tumor-imaging method targeting cancer-associated fibroblasts. J Nucl Med. 2018;59:1423-1429. 
12. Assadi M, Rekabpour SJ, Jafari E, et al. Feasibility and therapeutic potential of $177 \mathrm{Lu}$-fibroblast activation protein inhibitor-46 for patients with relapsed or refractory cancers: a preliminary study. Clin Nucl Med. 2021. Epub ahead of print.

13. Baum RP, Schuchardt C, Singh A, et al. Feasibility, biodistribution and preliminary dosimetry in peptide-targeted radionuclide therapy (PTRT) of diverse adenocarcinomas using (177)Lu-FAP-2286: first-in-human results. J NuCl Med. 2021. Epub ahead of print.

14. Toms J, Kogler J, Maschauer S, et al. Targeting fibroblast activation protein: radiosynthesis and preclinical evaluation of an (18)F-labeled FAP inhibitor. J Nucl Med. 2020;61:1806-1813.

15. Hidalgo M, Amant F, Biankin AV, et al. Patient-derived xenograft models: an emerging platform for translational cancer research. Cancer Discov. 2014;4:998-1013.

16. Lang L, Li W, Guo N, et al. Comparison study of [18F]FAI-NOTA-PRGD2, [18F]FPPRGD2, and [68Ga]Ga-NOTA-PRGD2 for PET imaging of U87MG tumors in mice. Bioconjug Chem. 2011;22:2415-2422.

17. Li ZB, Cai W, Cao Q, et al. (64)Cu-labeled tetrameric and octameric RGD peptides for small-animal PET of tumor alpha(v)beta(3) integrin expression. J NuCl Med. 2007;48:1162-1171.

18. Wu Z, Li ZB, Chen K, et al. MicroPET of tumor integrin alphavbeta3 expression using 18F-labeled PEGylated tetrameric RGD peptide (18F-FPRGD4). J Nucl Med. 2007;48:1536-1544.

19. Zhao L, Chen H, Guo Z, et al. Targeted radionuclide therapy in patient-derived xenografts using (177)Lu-EB-RGD. Mol Cancer Ther. 2020;19:2034-2043.

20. Chen H, Zhao L, Fu K, et al. Integrin alphavbeta3-targeted radionuclide therapy combined with immune checkpoint blockade immunotherapy synergistically enhances anti-tumor efficacy.

Theranostics. 2019;9:7948-7960.

21. Chen H, Pang Y, Wu J, et al. Comparison of [(68)Ga]Ga-DOTA-FAPI-04 and [(18)F] FDG PET/CT for the diagnosis of primary and metastatic lesions in patients with various types of cancer. Eur J NuCl Med Mol Imaging. 2020. Epub ahead of print.

22. Stabin MG, Sparks RB, Crowe E. OLINDA/EXM: the second-generation personal computer software for internal dose assessment in nuclear medicine. J Nucl Med. 2005;46:1023-1027. 
23. Meyer C, Dahlbom M, Lindner T, et al. Radiation dosimetry and biodistribution of (68)Ga-FAPI-46 PET imaging in cancer patients. J Nucl Med. 2020;61:1171-1177.

24. Jokar N, Velikyan I, Ahmadzadehfar H, et al. Theranostic approach in breast cancer: a treasured tailor for future oncology. Clin Nucl Med. 2021;46:e410-e420.

25. Wang $\mathrm{S}$, Zhou X, Xu X, et al. Clinical translational evaluation of Al(18)F-NOTA-FAPI for fibroblast activation protein-targeted tumour imaging. Eur J Nucl Med Mol Imaging. 2021. Epub ahead of print.

26. Liu S. Radiolabeled cyclic RGD peptides as integrin alpha(v)beta(3)-targeted radiotracers: maximizing binding affinity via bivalency. Bioconjug Chem. 2009;20:2199-2213.

27. Li ZB, Chen K, Chen X. (68)Ga-labeled multimeric RGD peptides for microPET imaging of integrin alpha(v)beta (3) expression. Eur J Nucl Med Mol Imaging. 2008;35:1100-1108. 


\section{Figures}

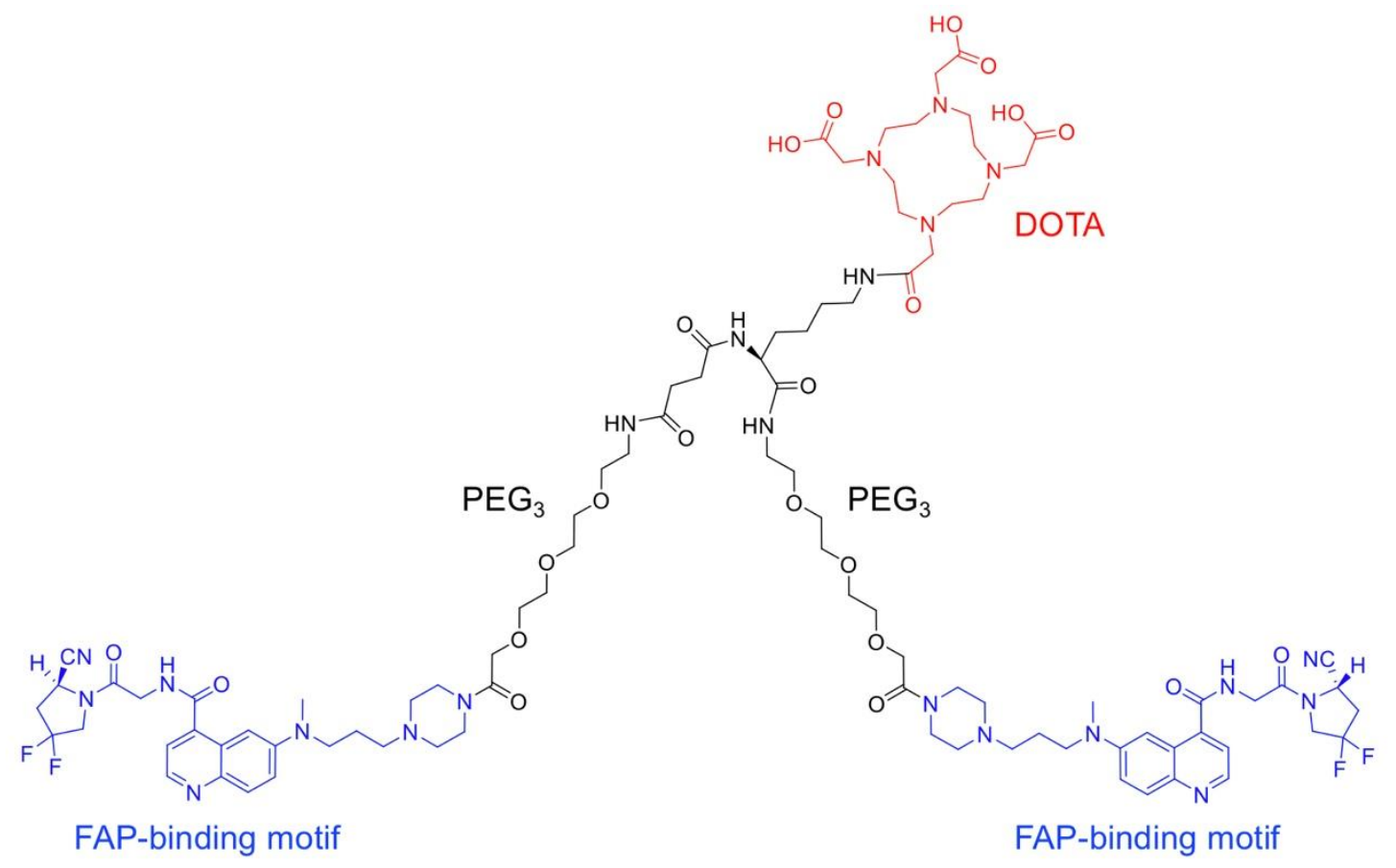

FIGURE 1. Chemical structure of DOTA-2P(FAPI)2. 
A

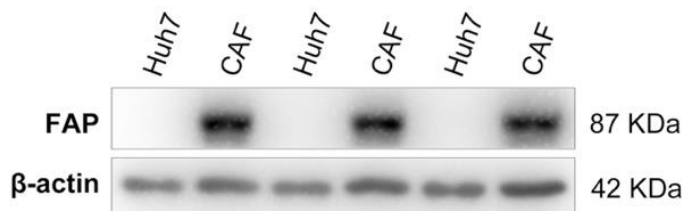

C

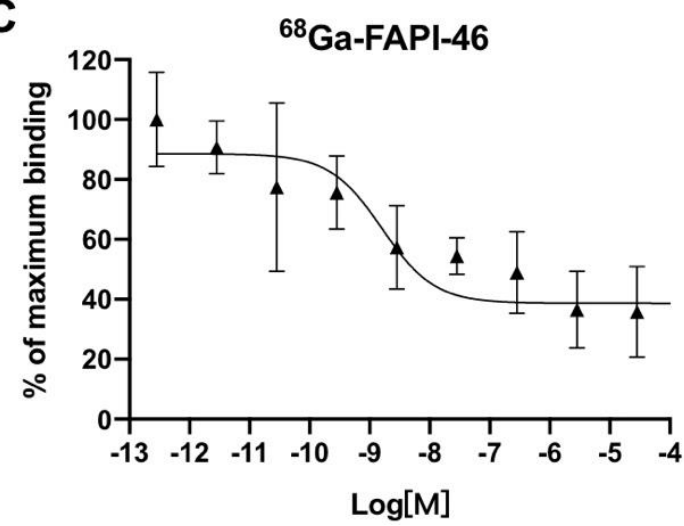

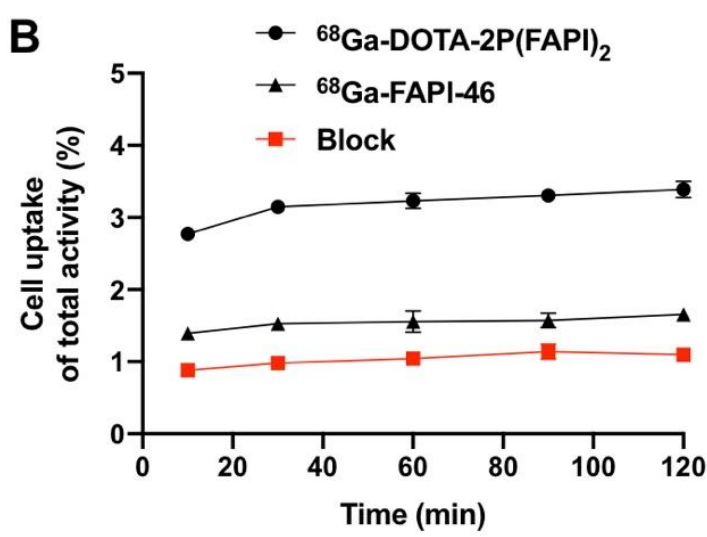

D

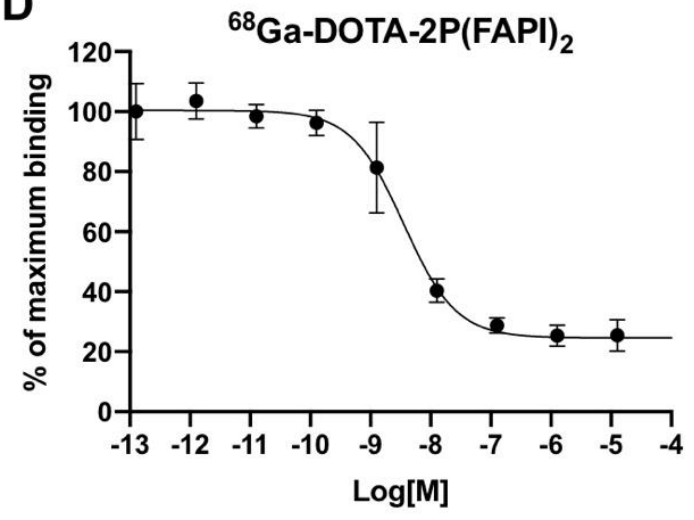

FIGURE 2. (A) Fibroblast activation protein (FAP) expression in Huh7 cells and cancer-associated fibroblasts assayed using western blotting. (B) Cell uptake assay of ${ }^{68} \mathrm{Ga}-\mathrm{DOTA}-2 \mathrm{P}(\mathrm{FAPI}) 2,{ }^{68} \mathrm{Ga}-\mathrm{FAPI}-46$, and blocking experiment on CAFs $(n=3)$. (C) Inhibition of ${ }^{68} \mathrm{Ga}-\mathrm{FAPI}-46$ binding to FAP on CAFs by unlabeled FAPI-46 $\left(2.83 \times 10^{-4}\right.$ to $\left.10^{-13} \mathrm{M} ; \mathrm{n}=3\right)$. (D) Inhibition of ${ }^{68} \mathrm{Ga}-\mathrm{DOTA}-2 \mathrm{P}(\mathrm{FAPI}) 2$ binding to FAP on CAFs by unlabeled FAPI-46 $\left(1.27 \times 10^{-4}\right.$ to $\left.10^{-13} \mathrm{M} ; \mathrm{n}=3\right)$. CAFs: cancer-associated fibroblasts. 


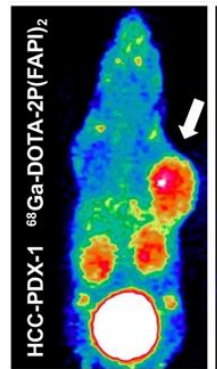

$0.5 \mathrm{~h}$

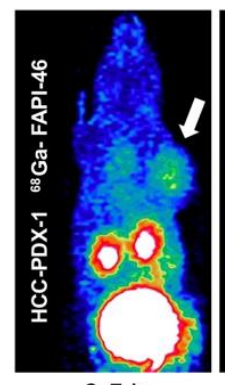

$0.5 \mathrm{~h}$

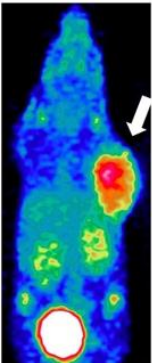

$1 \mathrm{~h}$

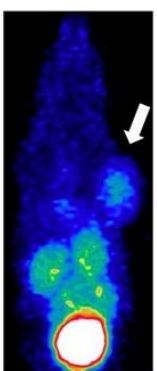

$1 \mathrm{~h}$

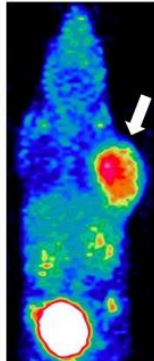

$2 \mathrm{~h}$

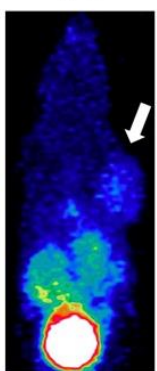

$2 \mathrm{~h}$

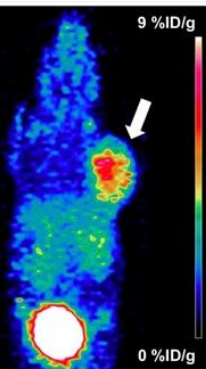

$4 \mathrm{~h}$

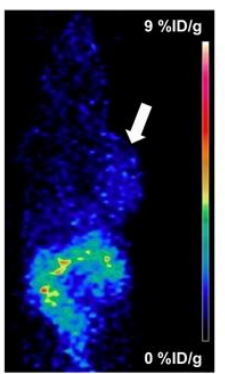

$4 \mathrm{~h}$

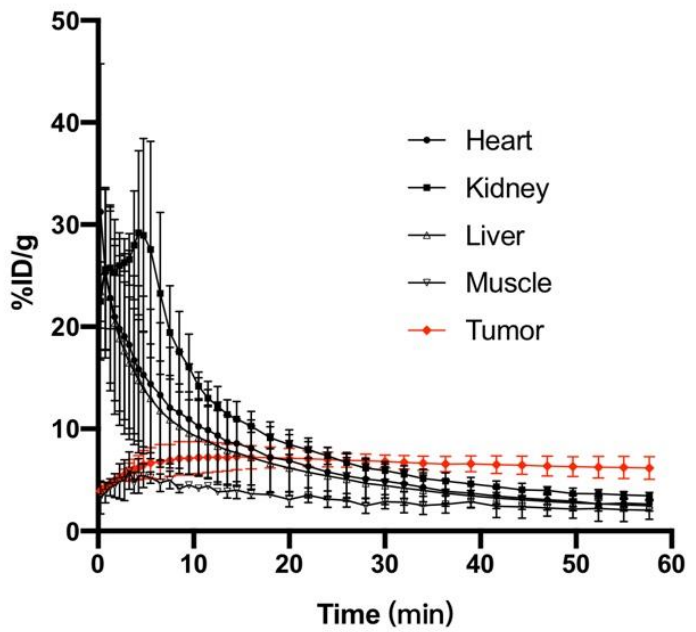

FIGURE 3. Representative static PET imaging of ${ }^{68} \mathrm{Ga}-\mathrm{DOTA}-2 \mathrm{P}(\mathrm{FAPI})_{2}$ and

${ }^{68} \mathrm{Ga}-\mathrm{FAPI}-46$ in HCC-PDX-1, and dynamic time-activity curves of

${ }^{68} \mathrm{Ga}-\mathrm{DOTA}-2 \mathrm{P}(\mathrm{FAPI})_{2}$ in the heart, kidney, liver, muscle, and tumor tissues. 


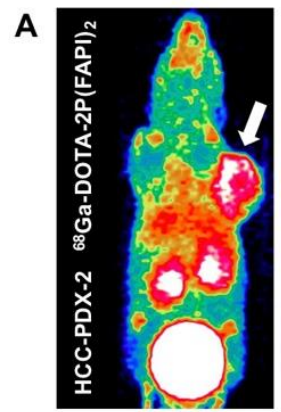

$0.5 \mathrm{~h}$

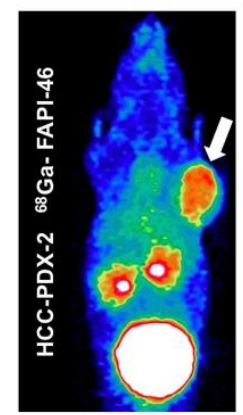

$0.5 \mathrm{~h}$

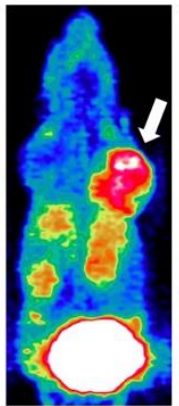

$1 \mathrm{~h}$

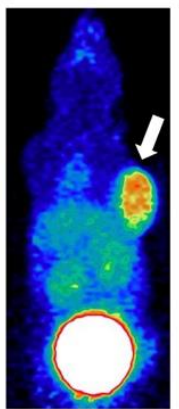

$1 \mathrm{~h}$

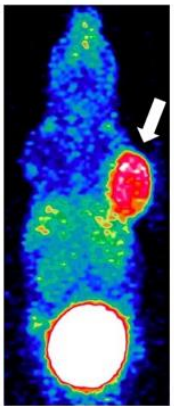

$2 \mathrm{~h}$

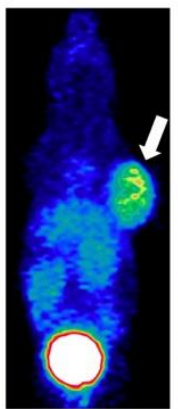

$2 \mathrm{~h}$

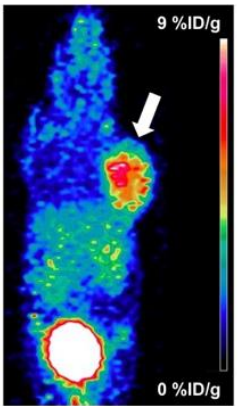

$4 \mathrm{~h}$

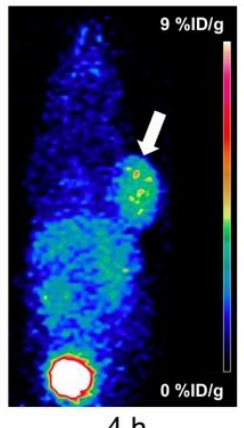

B

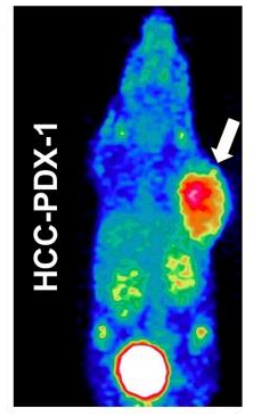

Without competitor

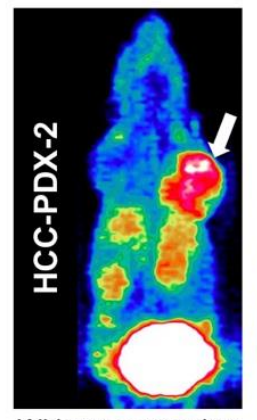

Without competitor

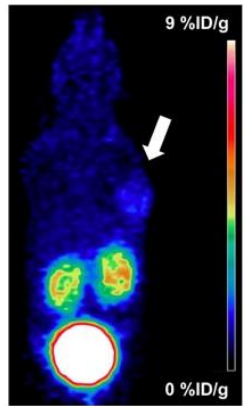

With competitor

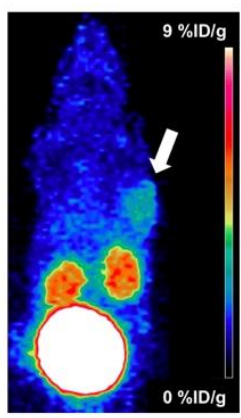

With competitor

FIGURE 4. (A) Representative static PET imaging of ${ }^{68} \mathrm{Ga}-\mathrm{DOTA}-2 \mathrm{P}(\mathrm{FAPI})_{2}$ and ${ }^{68} \mathrm{Ga}-\mathrm{FAPI}-46$ in HCC-PDX-2. (B) Representative static PET imaging of ${ }^{68} \mathrm{Ga}-\mathrm{DOTA}-2 \mathrm{P}(\mathrm{FAPI})_{2}$ in HCC-PDX-1 and HCC-PDX-2 with and without simultaneous injection of unlabeled FAPI-46 as competitor $1 \mathrm{~h}$ after administration. 

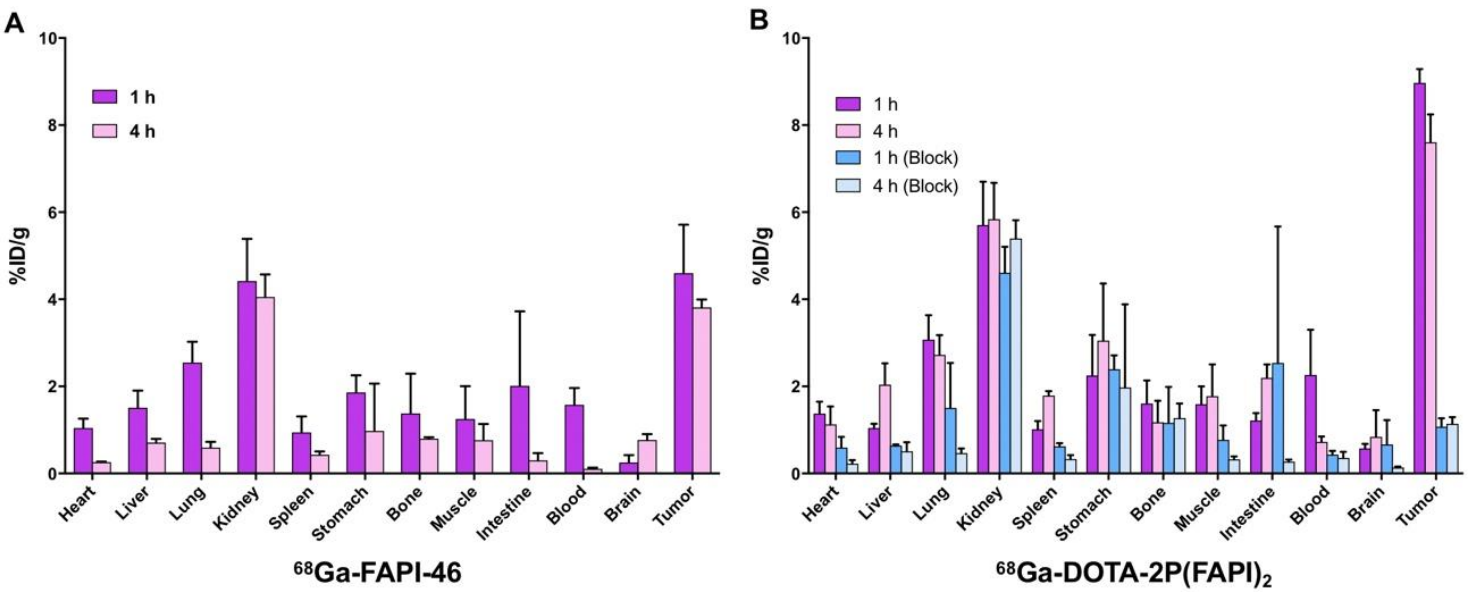

FIGURE 5. (A) Ex-vivo biodistribution of ${ }^{68} \mathrm{Ga}-\mathrm{FAPI}-46$ in HCC-PDX-1, 1 and $4 \mathrm{~h}$ post-injection ( $\mathrm{n}=3 /$ group); (B) Ex-vivo biodistribution of ${ }^{68} \mathrm{Ga}-\mathrm{DOTA}-2 \mathrm{P}(\mathrm{FAPI}) 2$ in HCC-PDX-1, 1 and $4 \mathrm{~h}$ post-injection, with and without co-administration of unlabeled FAPI-46 as a blocking agent ( $n=3 /$ group). 

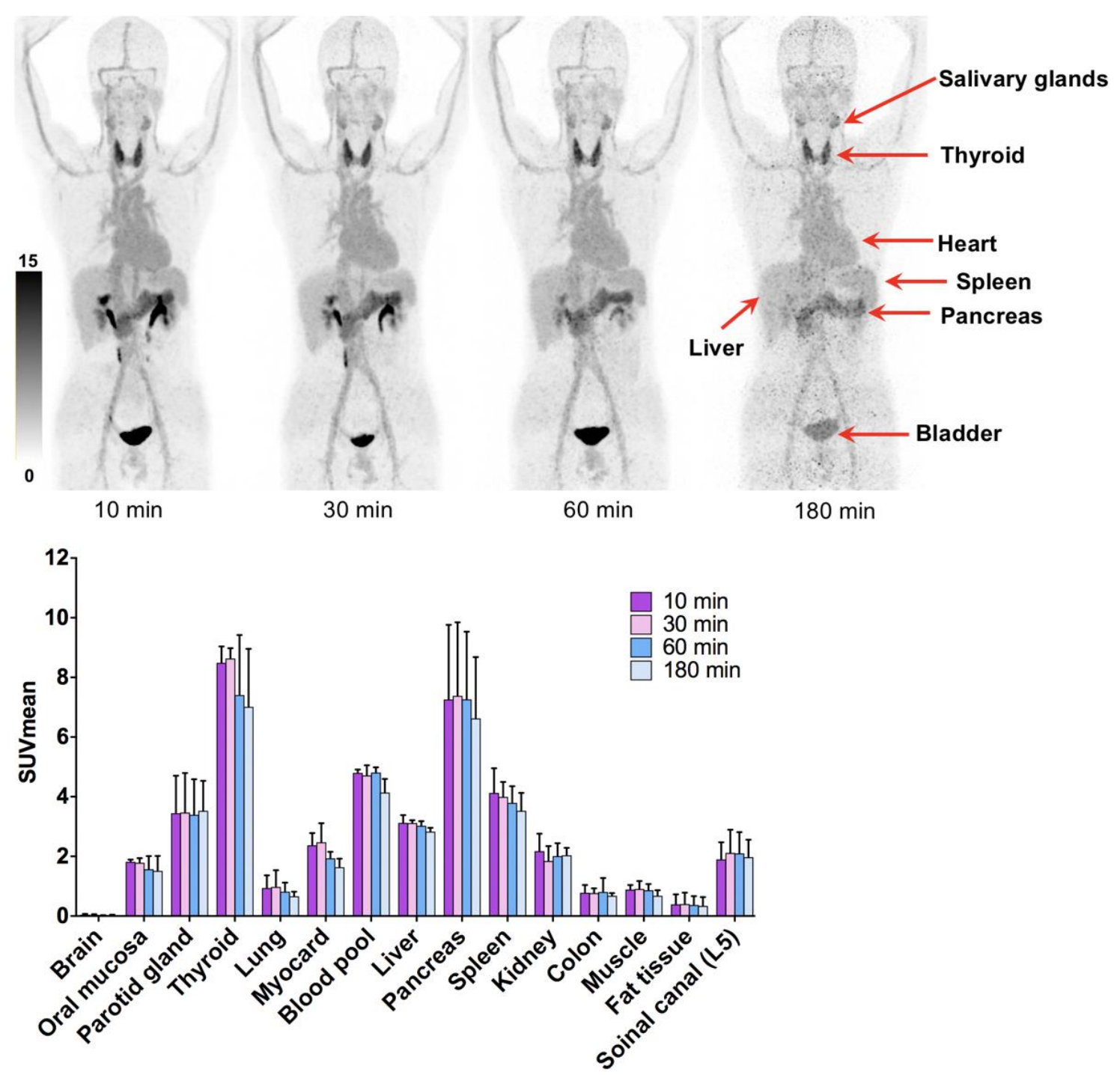

FIGURE 6. ${ }^{68} \mathrm{Ga}-\mathrm{DOTA}-2 \mathrm{P}(\mathrm{FAPI}) 2$ 10, 30, 60, and $180 \mathrm{~min}$ after injection in healthy volunteers, and the SUVmean values of healthy organs at different time points. 

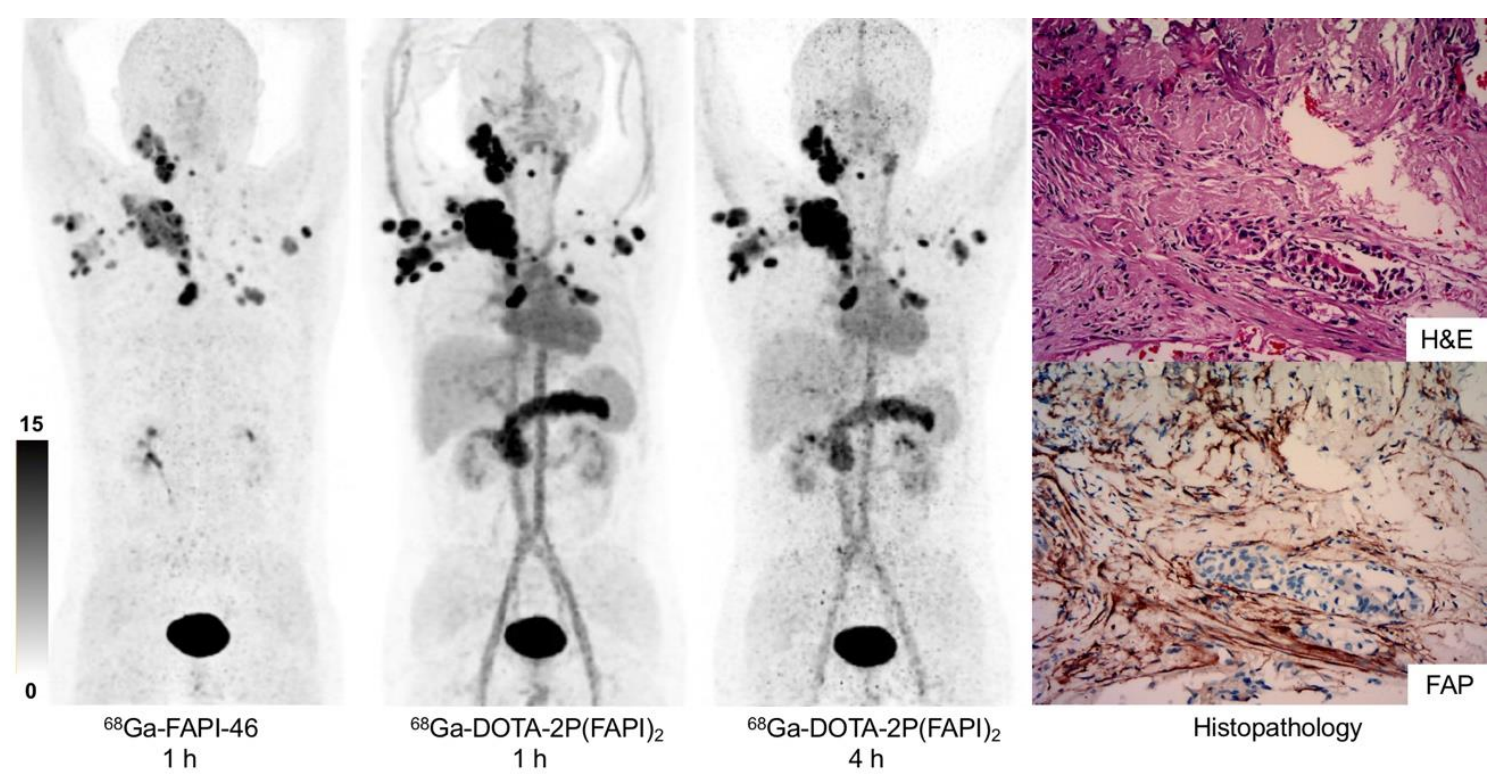

FIGURE 7. ${ }^{68} \mathrm{Ga}-\mathrm{FAPI}-46,1 \mathrm{~h}$ after injection, and ${ }^{68} \mathrm{Ga}-\mathrm{DOTA}-2 \mathrm{P}(\mathrm{FAPI}) 2,1$ and 4 $\mathrm{h}$ after injection, in a patient with metastatic thyroid cancer. Hematoxylin and eosin (H\&E) staining and FAP immunohistochemistry staining showed high FAP expression in the tumor stroma (original magnification, $\times 100$ ). 


\section{Tables}

Table $1{ }^{68} \mathrm{Ga}$-DOTA-2P(FAPI)2 dosimetry summary of effective doses using OLINDA/EXM v.1.1.

\begin{tabular}{lll}
\hline Target organ & $\begin{array}{l}\text { Mean } \\
(\mathrm{mSv} / \mathrm{MBq})\end{array}$ & $\begin{array}{l}\text { SD } \\
(\mathrm{mSv} / \mathrm{MBq})\end{array}$ \\
\hline Adrenal glands & $7.98 \mathrm{E}-05$ & $3.04 \mathrm{E}-05$ \\
Brain & $3.16 \mathrm{E}-05$ & $1.96 \mathrm{E}-05$ \\
Breasts & $6.36 \mathrm{E}-05$ & $1.09 \mathrm{E}-05$ \\
Gallbladder Wall & - & - \\
LLI Wall & $9.22 \mathrm{E}-04$ & $2.33 \mathrm{E}-04$ \\
Small Intestine & $5.18 \mathrm{E}-05$ & $1.84 \mathrm{E}-05$ \\
Stomach Wall & $7.12 \mathrm{E}-04$ & $3.16 \mathrm{E}-05$ \\
ULI Wall & $2.79 \mathrm{E}-05$ & $1.13 \mathrm{E}-05$ \\
Heart Wall & - & - \\
Kidneys & $1.01 \mathrm{E}-04$ & $4.96 \mathrm{E}-05$ \\
Liver & $1.65 \mathrm{E}-03$ & $4.12 \mathrm{E}-04$ \\
Lungs & $1.36 \mathrm{E}-03$ & $4.59 \mathrm{E}-04$ \\
Muscle & $4.19 \mathrm{E}-05$ & $2.07 \mathrm{E}-05$ \\
Ovaries & $5.94 \mathrm{E}-04$ & $1.06 \mathrm{E}-04$ \\
Pancreas & $7.61 \mathrm{E}-04$ & $8.05 \mathrm{E}-04$ \\
Red Marrow & $1.12 \mathrm{E}-03$ & $1.33 \mathrm{E}-04$ \\
Osteogenic Cells & $6.47 \mathrm{E}-05$ & $6.87 \mathrm{E}-06$ \\
Skin & $1.22 \mathrm{E}-05$ & $2.32 \mathrm{E}-06$ \\
Spleen & $1.58 \mathrm{E}-04$ & $9.12 \mathrm{E}-05$ \\
Thymus & $9.64 \mathrm{E}-06$ & $4.47 \mathrm{E}-06$ \\
Thyroid & $3.11 \mathrm{E}-03$ & $4.68 \mathrm{E}-04$ \\
Urinary Bladder Wall & $1.04 \mathrm{E}-03$ & $5.22 \mathrm{E}-04$ \\
Uterus & $1.27 \mathrm{E}-05$ & $6.00 \mathrm{E}-06$ \\
Effective Dose Equivalent & $1.69 \mathrm{E}-02$ & $1.92 \mathrm{E}-03$ \\
Effective Dose & $1.19 \mathrm{E}-02$ & $9.45 \mathrm{E}-04$ \\
\hline & & \\
\hline
\end{tabular}

LLI: lower large intestine; SD: standard deviation; ULI: upper large intestine. 


\section{Graphical Abstract}
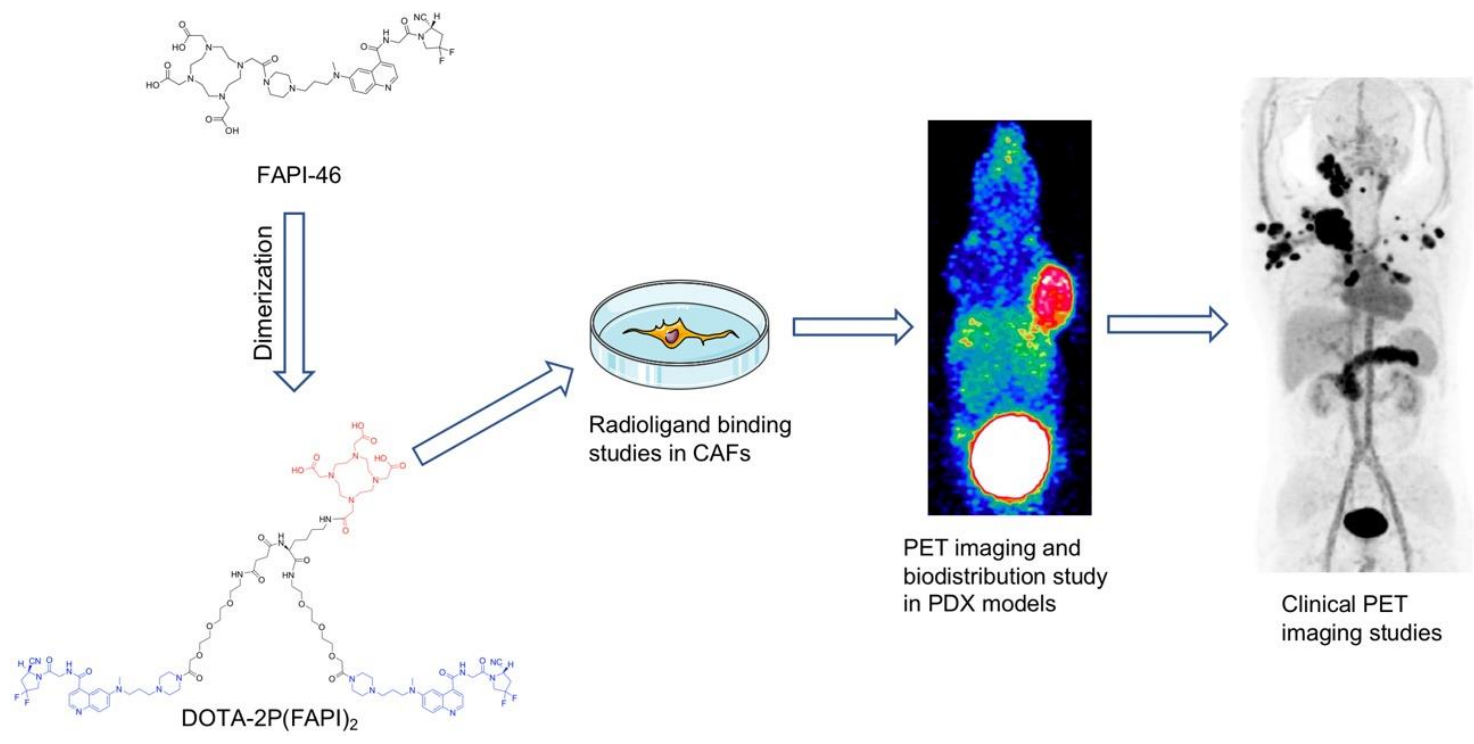


\section{Supplemental materials}

\section{Chemicals and Reagents}

All chemicals were purchased from Energy Chemical Co. and Nanchang

Tanzhen Biological Technology Co., Ltd.; FAPI-46 was purchased from C.S. Bio.

Anti-FAP mAb was purchased from Abcam (Cat. No. ab207178) and Abclonal

(Cat. No. A6349). The human hepatocellular carcinoma (HCC) cell line Huh7 was

purchased from the China National Infrastructure of Cell Line Resource. The

CAFs from surgical specimens of HCC patients were kindly provided by Dr.

Dongyan Shen (The First Affiliated Hospital of Xiamen University, Xiamen

University, China). The labeling efficiency and radiochemical purity were tested

using a radio-TLC scanner (MSFC1-00220, Eckert \& Ziegler) Dionex Ulti-Mate

3000 high-performance liquid chromatography (HPLC; Thermo Scientific), an

SPD-20A UV detector $(\lambda=254 \mathrm{~nm})$, and an Elysia Raytest Gabi Star $\gamma$-radiation

detector. Radioactivity (counts per minute) was measured using a $\mathrm{y}$-counter

(WIZARD 2480; Perkin-Elmer) and CRC-25R dose calibrators (CAPIN-TEC Inc.). 


\section{Procedure of DOTA-2P(FAPI)2 synthesis}

Compound 2 (500 mg, $1 \mathrm{mmol})$ and Boc-PEG3-OH (338 mg, $1.1 \mathrm{mmol})$ in DMF (3 mL) were treated with HATU $(570 \mathrm{mg}, 1.5 \mathrm{mmol})$ and DIPEA $(710 \mathrm{mg}$, $5.5 \mathrm{mmol})$. The reaction mixture was stirred for $16 \mathrm{~h}$ at $80^{\circ} \mathrm{C}$. After completion of the reaction, the mixture was transferred into an ice bath and TFA $(1.15 \mathrm{~mL}, 15$ $\mathrm{mmol}$ ) was added dropwise. After another $3 \mathrm{~h}$ of stirring at room temperature, the mixture was adjusted to $\mathrm{pH}=5.5$ by $\mathrm{NaOH}$ solution and purified by prep-HPLC to afford $200 \mathrm{mg}$ of compound 3. LC-MS (ESI+): m/z $689.6[\mathrm{M}+\mathrm{H}]+, 345.4$ $[\mathrm{M}+2 \mathrm{H}]+/ 2$.

Compound $3(68.9 \mathrm{mg}, 0.1 \mathrm{mmol})$ and compound $4(56 \mathrm{mg}, 1.1 \mathrm{mmol})$ in DMF $(1 \mathrm{~mL})$ were treated with HATU $(57 \mathrm{mg}, 0.15 \mathrm{mmol})$ and DIPEA $(71 \mathrm{mg}$, $0.55 \mathrm{mmol})$. The reaction mixture was stirred for $8 \mathrm{~h}$ at $80^{\circ} \mathrm{C}$. After completion of the reaction, the mixture was transferred into an ice bath and TFA $(0.2 \mathrm{~mL}, 1.8$ mmol) was added dropwise. After another $1 \mathrm{~h}$ of stirring at room temperature, the mixture was adjusted to $\mathrm{pH}=5.5$ by $\mathrm{NaOH}$ solution and purified by prep-HPLC to afford compound 5 (50 mg). LC-MS (ESI+): m/z $1039.9[\mathrm{M}+\mathrm{H}]+, 520.5$ $[\mathrm{M}+2 \mathrm{H}]+/ 2$.

Compound 5 (30 mg, $0.028 \mathrm{mmol})$ and compound $6(20 \mathrm{mg}, 0.035 \mathrm{mmol})$ were dissolved in DMF $(1.5 \mathrm{~mL})$ and treated with HATU $(16 \mathrm{mg}, 0.042 \mathrm{mmol})$ and 
DIPEA (20 mg, $0.154 \mathrm{mmol})$. The reaction mixture was stirred for $6 \mathrm{~h}$ at room temperature. After completion of the reaction, DMF was removed under reduced pressure, and $25 \%$ DEA/THF (1 mL) was added dropwise. After another $1 \mathrm{~h}$ of stirring at room temperature, the mixture was purified by prep-HPLC to afford compound 7 (10 mg). LC-MS (ESI+): $\mathrm{m} / \mathrm{z} 686.8[\mathrm{M}+2 \mathrm{H}]^{+} / 2$

Compound 7 (16 mg, $0.01 \mathrm{mmol})$ and Compound $8(9.5 \mathrm{mg}, 0.011 \mathrm{mmol})$ in DMF (1 mL) were treated with HATU $(5.7 \mathrm{mg}, 0.015 \mathrm{mmol})$ followed by DIPEA (7.1 $\mathrm{mg}, 0.055 \mathrm{mmol})$. The reaction mixture was stirred for $4 \mathrm{~h}$ at $80^{\circ} \mathrm{C}$. After completion of the reaction, the mixture was transferred into an ice bath and TFA $(0.02 \mathrm{~mL}, 0.18 \mathrm{mmol})$ dropwise. After another $1 \mathrm{~h}$ of stirring at room temperature, the mixture was adjusted to $\mathrm{pH} 5.5$ by $\mathrm{NaOH}$ solution and purified by prep-HPLC to afford compound 9 (5 mg). LC-MS (ESI+): m/z $659.3[\mathrm{M}+3 \mathrm{H}]^{+} / 3$. 


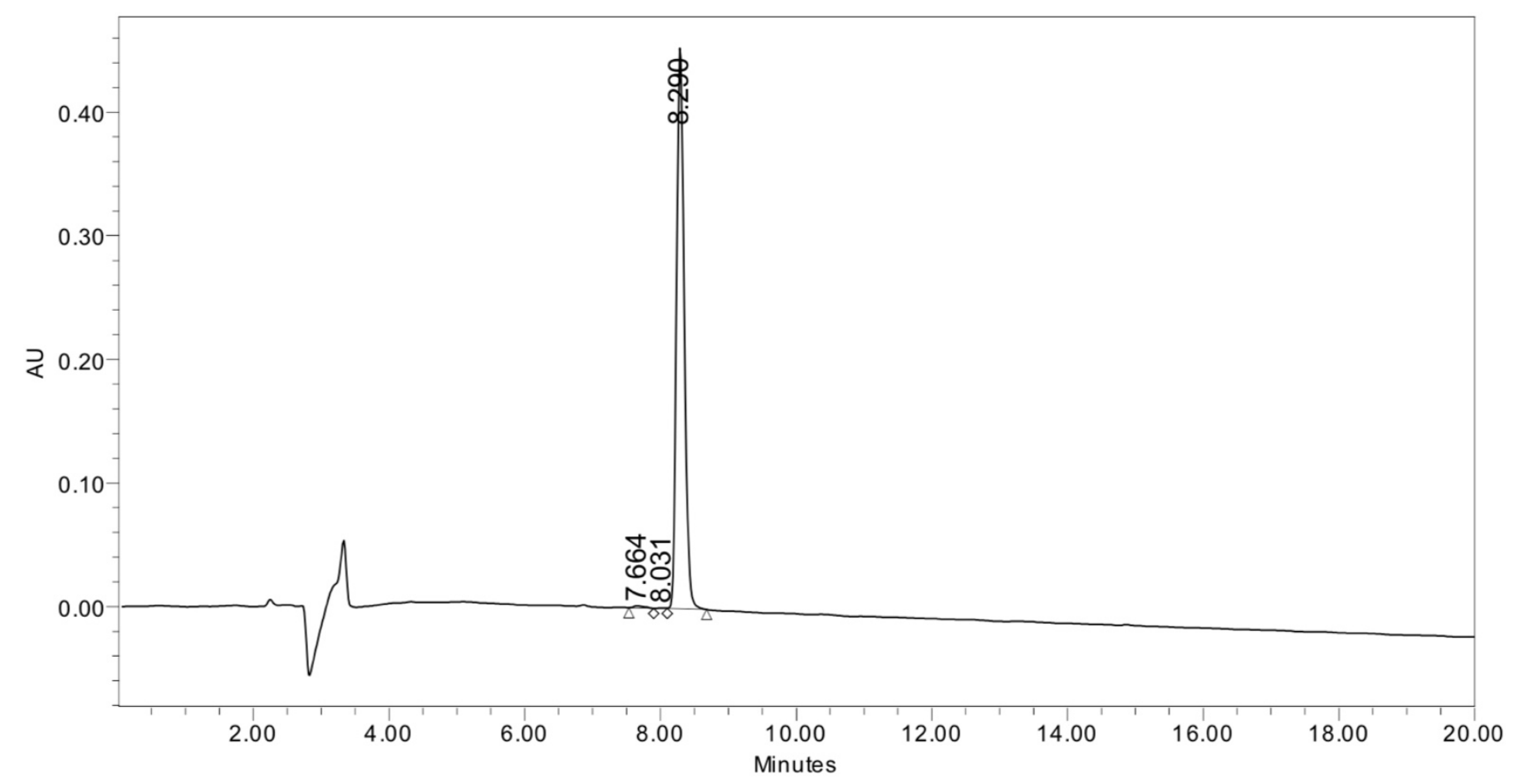

\begin{tabular}{|r|c|r|r|r|r|}
\hline & RT & Area & \% Height & $\begin{array}{c}\text { Width } \\
(\mathrm{sec})\end{array}$ & $\%$ Area \\
\hline 1 & 7.664 & 16974 & 0.36 & 22.000 & 0.48 \\
\hline 2 & 8.031 & 3271 & 0.10 & 12.000 & 0.09 \\
\hline 3 & 8.290 & 3545868 & 99.54 & 35.000 & 99.43 \\
\hline
\end{tabular}

The high-performance liquid chromatography (HPLC) of DOTA-2P(FAPI)2 


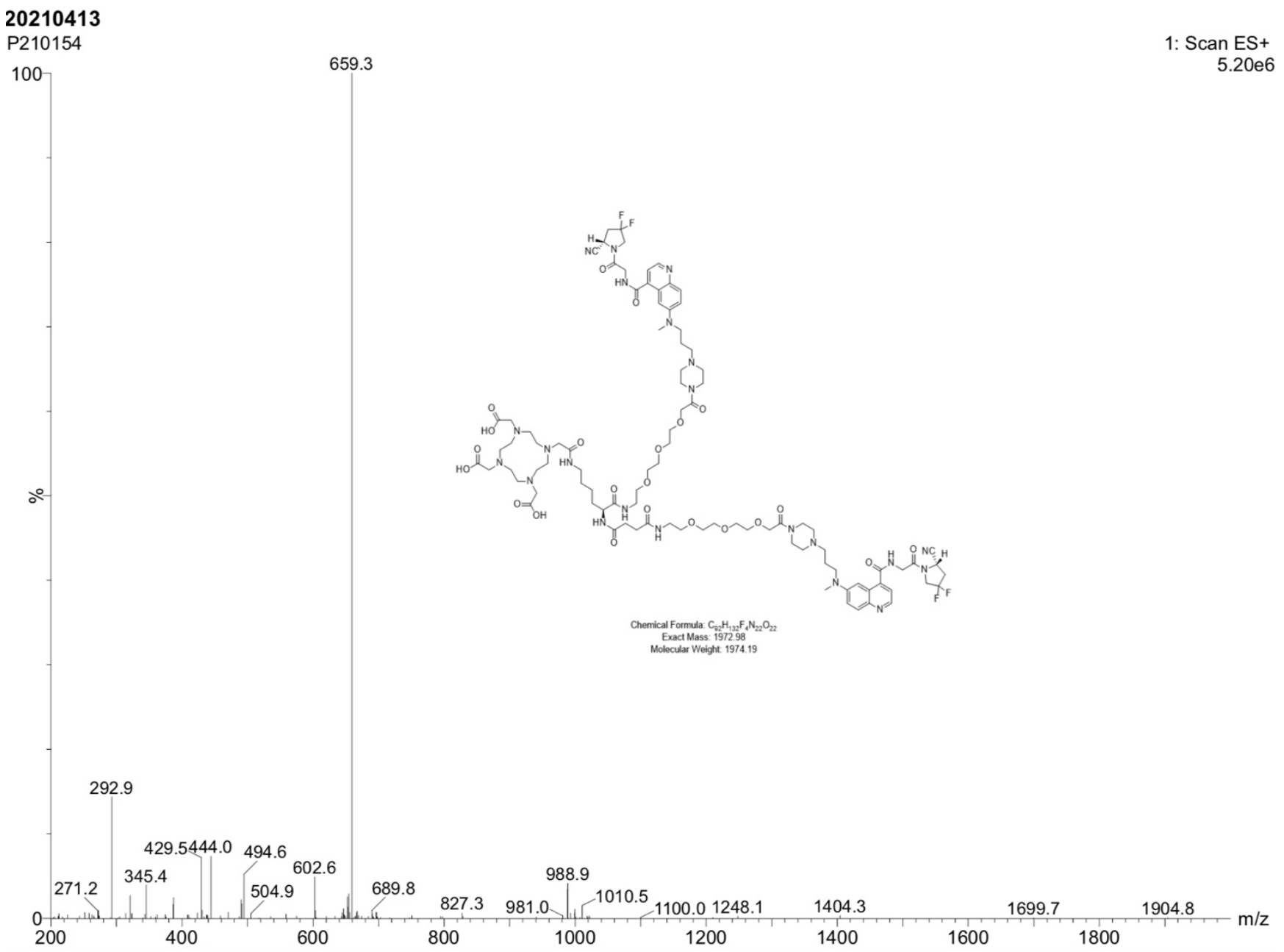

The liquid chromatography-mass spectrometry of DOTA-2P(FAPI)2. 


\section{Radio-HPLC}

HPLC chromatogram analysis was performed using the analytic C-18 reversedphase column $(4.6 \times 250 \mathrm{~mm}, 5 \mu \mathrm{m}, 120 \AA$, Thermo $)$.

HPLC conditions were as follows: trifluoroacetic acid (TFA) $(0.1 \%)$ and $\mathrm{CH}_{3} \mathrm{CN}$

$(0.1 \% \mathrm{TFA})$ flow rate $=1 \mathrm{~mL} / \mathrm{min} ; \lambda=254 \mathrm{~nm} ; \mathrm{A}=0.1 \%$ trifluoroacetic acid

(TFA) $/ \mathrm{H}_{2} \mathrm{O} ; \mathrm{B}=0.1 \%$ TFA/acetonitrile. $\mathrm{B}$ gradient: $0-16 \mathrm{~min}$, from $5 \%$ to $75 \%$;

$17-20 \mathrm{~min}$, from $75 \%$ to $95 \% ; 21-25 \mathrm{~min}, 95 \% ; 26-30 \mathrm{~min}, 5 \%$. The retention

time was 10.66 min for ${ }^{68} \mathrm{Ga}-\mathrm{DOTA}-2 \mathrm{P}(\mathrm{FAPI})_{2}$ and $9.41 \mathrm{~min}$ for ${ }^{68} \mathrm{Ga}-\mathrm{FAPI}-46$.

\section{PDX-models production}

The tumor specimens were obtained from surgical resection, and the hepatocellular carcinoma (HCC) specimens were immediately placed in DMEM (Cat. \#C11995599BT, Gibco, USA) supplemented with 2\% antibiotics (penicillin and streptomycin) and stored in an ice box. Immunodeficient BALB/c nude mice were bred under specific pathogen free (SPF) conditions at Xiamen University Laboratory Animal Center from founders originally obtained from Shanghai SLAC Laboratory Animal Co., Ltd (China). In brief, the necrotic tissue was removed from the fresh tumor specimen (less than $2 \mathrm{~h}$ after the surgery). Then the specimen were cut into approximately $30 \mathrm{~mm}^{3}$ pieces with scissors and washed 
three times by DMEM supplemented with $2 \%$ antibiotics before subcutaneous implantation into the mice right side of the trunk. All procedures were performed in super-clean benches. Tumor growth was monitored until it reached $1500 \mathrm{~mm}^{3}$, then the mice were sacrificed, and the tumor was minced for passaging to the next generation BALB/c nude mice. The remaining fragments were used for the histological verification, including western blot of FAP, immunohistochemistry staining of FAP and Ki67, and Hematoxylin and eosin (H\&E) staining.

\section{Western blot and histopathological staining}

Proteins were extracted with lysis buffer (150 mM NaCl, $50 \mathrm{mM}$ Tris- $\mathrm{HCl}$ [pH 8.0], 1mM EDTA and 1\% Triton X-100). Approximately $20 \mu \mathrm{g}$ of total protein per sample was separated by SDS-PAGE and transferred to a PVDF membrane (Millipore). The membranes were pre-incubated with 5\% skimmed milk in TBST

for $1 \mathrm{~h}$, followed by incubation with human FAP antibody (ab207178; Abcam). Membranes were washed with TBST three times and incubated with horseradish peroxidase-labelled secondary antibody, which was detected using an enhanced chemiluminescence detection system (C280, Azure).

Anti-FAP mAb (ab207178, Abcam and A6349, Abclonal) was used to label surgical specimens of HCC patients and mice tumors during 
immunohistochemistry (IHC). FAP expression IHC staining was conducted according to our previous protocol using the above mAb (1).

\section{Dynamic PET imaging and static PET imaging for mice}

For dynamic PET imaging, the duration of the scan was $60 \mathrm{~min}$, and the reconstruction frames were $10 \times 30 \mathrm{~s}, 10 \times 60 \mathrm{~s}, 10 \times 120 \mathrm{~s}$, and $9 \times 160 \mathrm{~s}$. For $10-$ min static PET imaging, the acquisition times were $0.5,1,2$, and $4 \mathrm{~h}$ post injection (p.i.). For the blocking experiment, $30 \mathrm{nmol}$ of unlabelled FAPI-46 was added to the solution of ${ }^{68} \mathrm{Ga}-\mathrm{DOTA}-2 \mathrm{P}(\mathrm{FAPI})_{2}$ before injection. Images were reconstructed iteratively using a 3D OPMAP 256.pPetRcn (Siemens), and converted to \% ID/g images. Regions of interest (ROIs) in the tumor, liver, heart, kidney, and muscle were counted on the PET images to quantify the radioactive signals.

The dose of intravenously injected ${ }^{68} \mathrm{Ga}-\mathrm{FAPI}-46$ and ${ }^{68} \mathrm{Ga}-\mathrm{DOTA}-2 \mathrm{P}(\mathrm{FAPI}) 2$ was calculated according to the patient's weight (1.8-2.2 MBq $[0.05-0.06 \mathrm{mCi}] / \mathrm{kg}$ for FAPI). The time interval in cancer patients between ${ }^{68} \mathrm{Ga}-\mathrm{DOTA}-2 \mathrm{P}(\mathrm{FAPI}) 2$ and ${ }^{68} \mathrm{Ga}-\mathrm{FAPI}-46$ was three days. For healthy volunteers, data were acquired using a hybrid PET/CT scanner (Discovery MI, GE Healthcare, Milwaukee, WI, USA) 
after $10 \mathrm{~min}, 30 \mathrm{~min}, 60 \mathrm{~min}$, and $180 \mathrm{~min}$ of intravenous injection. For cancer patients, PET/CT images were acquired after 60 min of intravenous injection (one patient was scanned twice at $60 \mathrm{~min}$ and $240 \mathrm{~min}$ p.i.). All scans and reconstruction were performed according to a previously described protocol (2). The maximum standard uptake values (SUVmax) were automatically calculated using a region of interest $(\mathrm{ROI})$ drawn on the transaxial images. 


\section{Supplemental Figures}
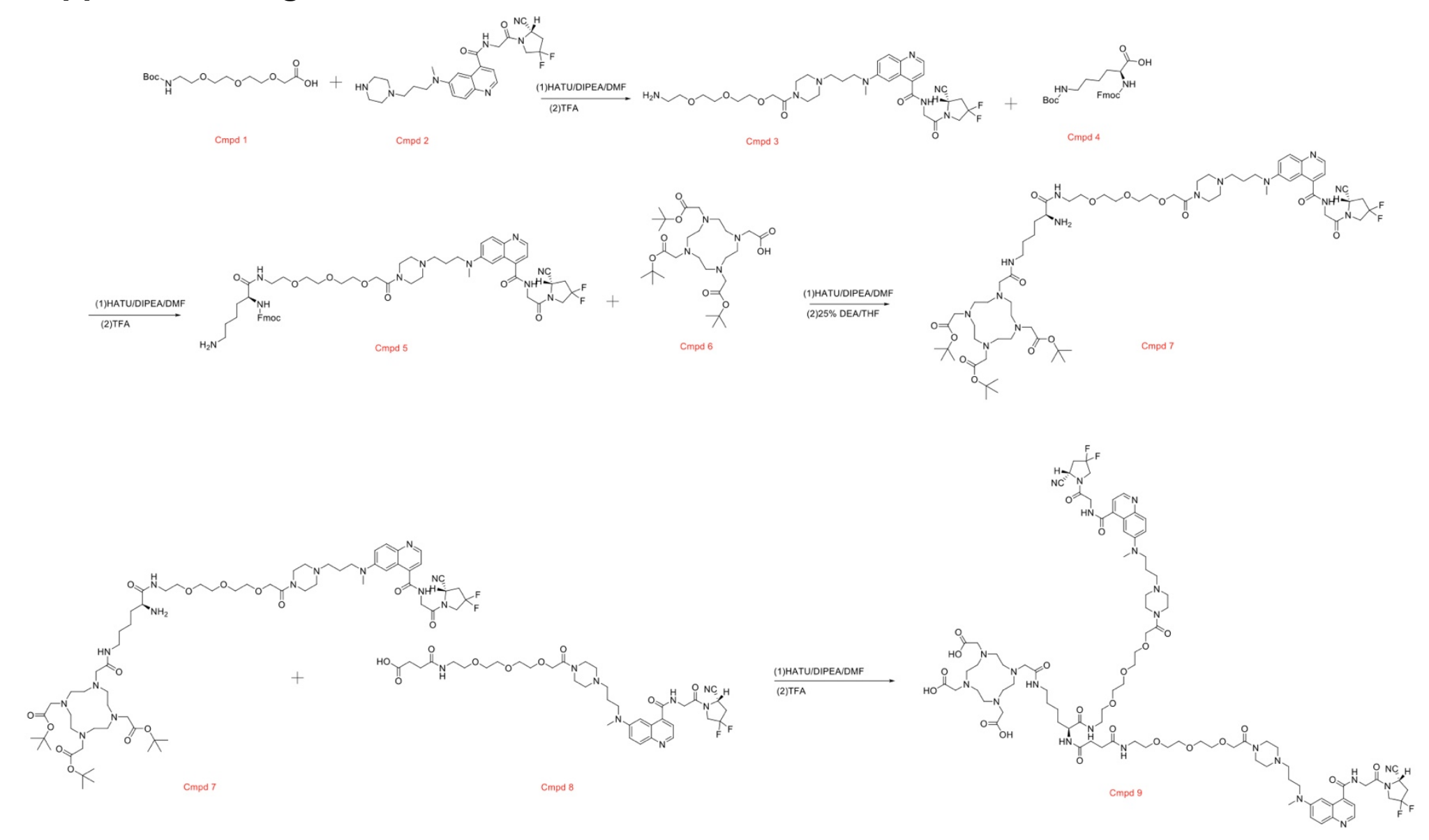

Supplemental Figure 1. Flow diagram of DOTA-2P(FAPI $)_{2}$ synthesis 

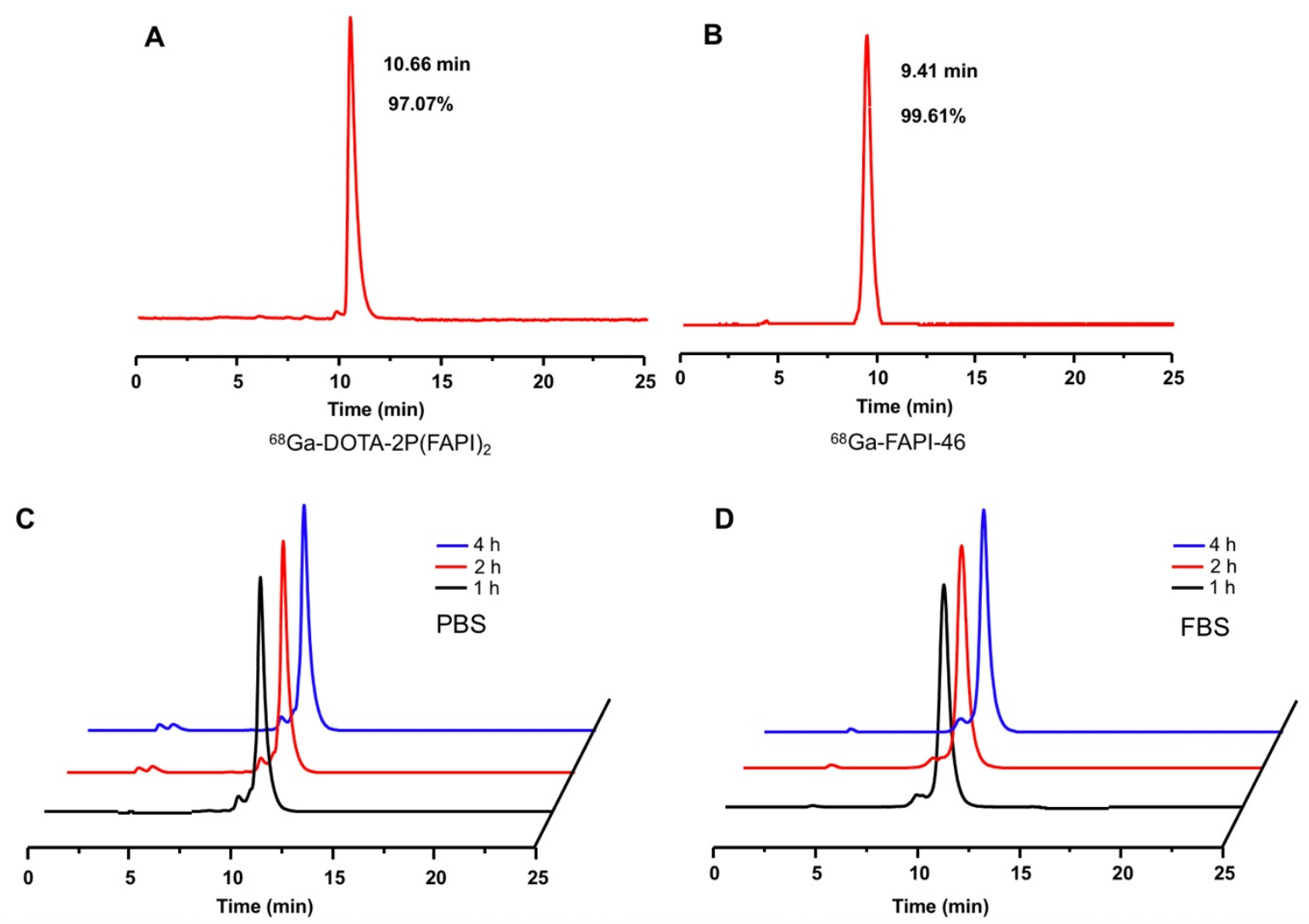

Supplemental Figure 2. (A, B) HPLC profiles of pure ${ }^{68} \mathrm{Ga}-\mathrm{DOTA}-2 \mathrm{P}(\mathrm{FAPI})_{2}$ and ${ }^{68} \mathrm{Ga}-\mathrm{FAPI}-46$, respectively; (C, D)

Stability of ${ }^{68} \mathrm{Ga}-\mathrm{DOTA}-2 \mathrm{P}(\mathrm{FAPI}) 2$ in phosphate buffer saline (PBS) and fetal bovine serum (FBS), respectively, 1, 2, and 4 $\mathrm{h}$ after incubation. 


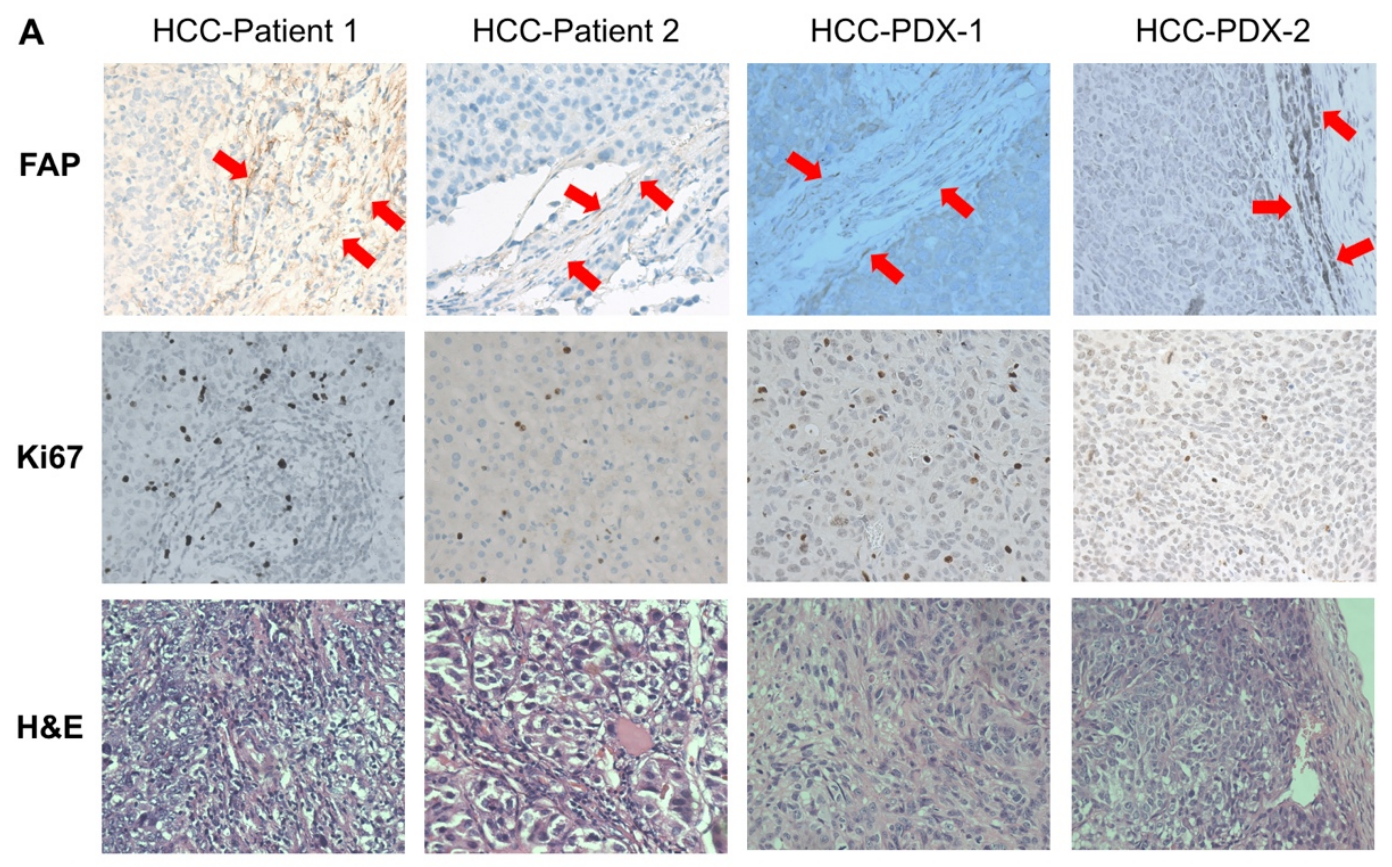

B

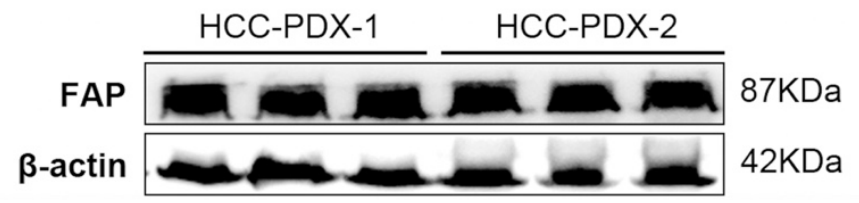

Supplemental Figure 3. (A) Immunohistochemistry staining of FAP and Ki67, and Hematoxylin and eosin (H\&E) staining in human hepatocellular carcinoma and corresponding PDXs (positive FAP in CAFs are indicated by arrows). (B) Western blot of FAP in PDXs 

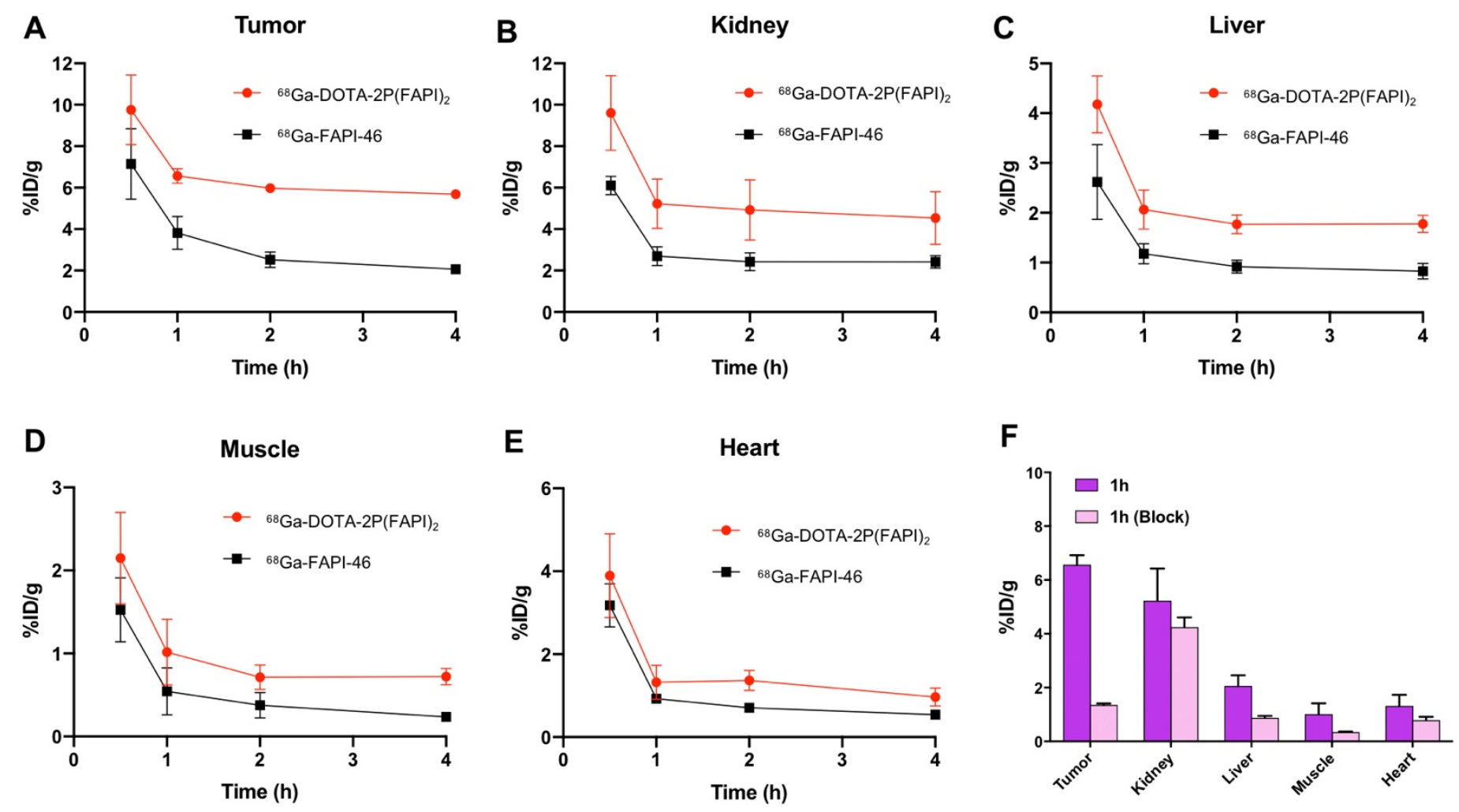

HCC-PDX-1

Supplemental Figure 4 (A-E) Comparison of tumor and organ uptake of ${ }^{68} \mathrm{Ga}-\mathrm{FAPI}-46$ and ${ }^{68} \mathrm{Ga}-\mathrm{DOTA}-2 \mathrm{P}(\mathrm{FAPI})_{2}$ in HCC-PDX-1 0.5, 1, 2, and 4 h post-injection ( $n=3 /$ group). $(F)$ Tumor and organ uptake of ${ }^{68}$ Ga-DOTA-2P(FAPI)2 in HCCPDX-1 $1 \mathrm{~h}$ post-injection with and without co-administration of unlabeled FAPI-46 as a blocking agent ( $\mathrm{n}=3 /$ group). 

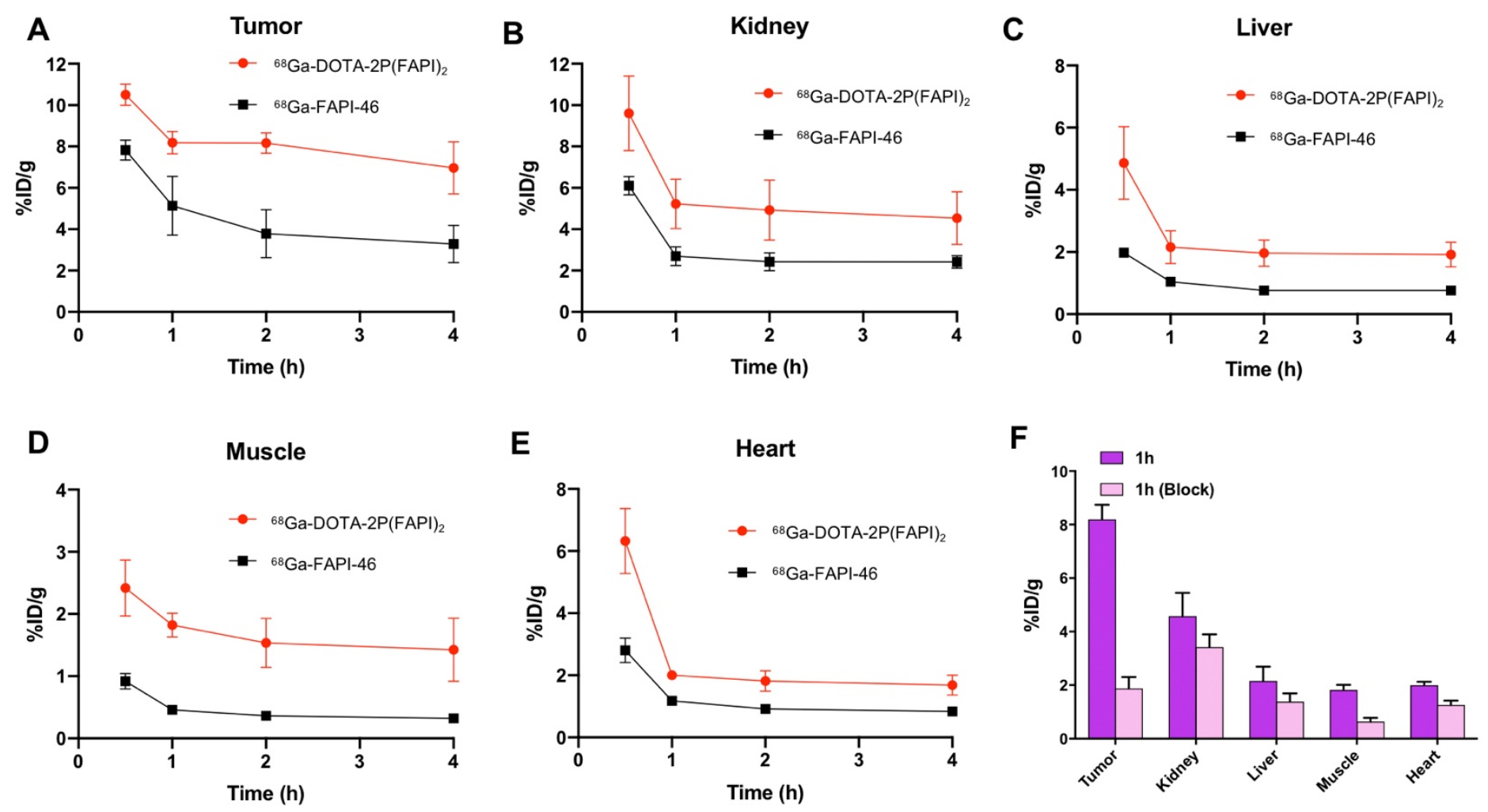

HCC-PDX-2

Supplemental Figure 5 (A-E) Comparison of tumor and organ uptake of ${ }^{68} \mathrm{Ga}-\mathrm{FAPI}-46$ and ${ }^{68} \mathrm{Ga}-\mathrm{DOTA}-2 \mathrm{P}(\mathrm{FAPI})_{2}$ in HCC-PDX-2 0.5, 1, 2, and 4 h post-injection ( $n=3 /$ group); (F) Tumor and organ uptake of ${ }^{68} \mathrm{Ga}$-DOTA-2P(FAPI)2 in HCCPDX-2 $1 \mathrm{~h}$ post-injection with and without co-administration of unlabeled FAPI-46 as a blocking agent ( $\mathrm{n}=3 /$ group). 


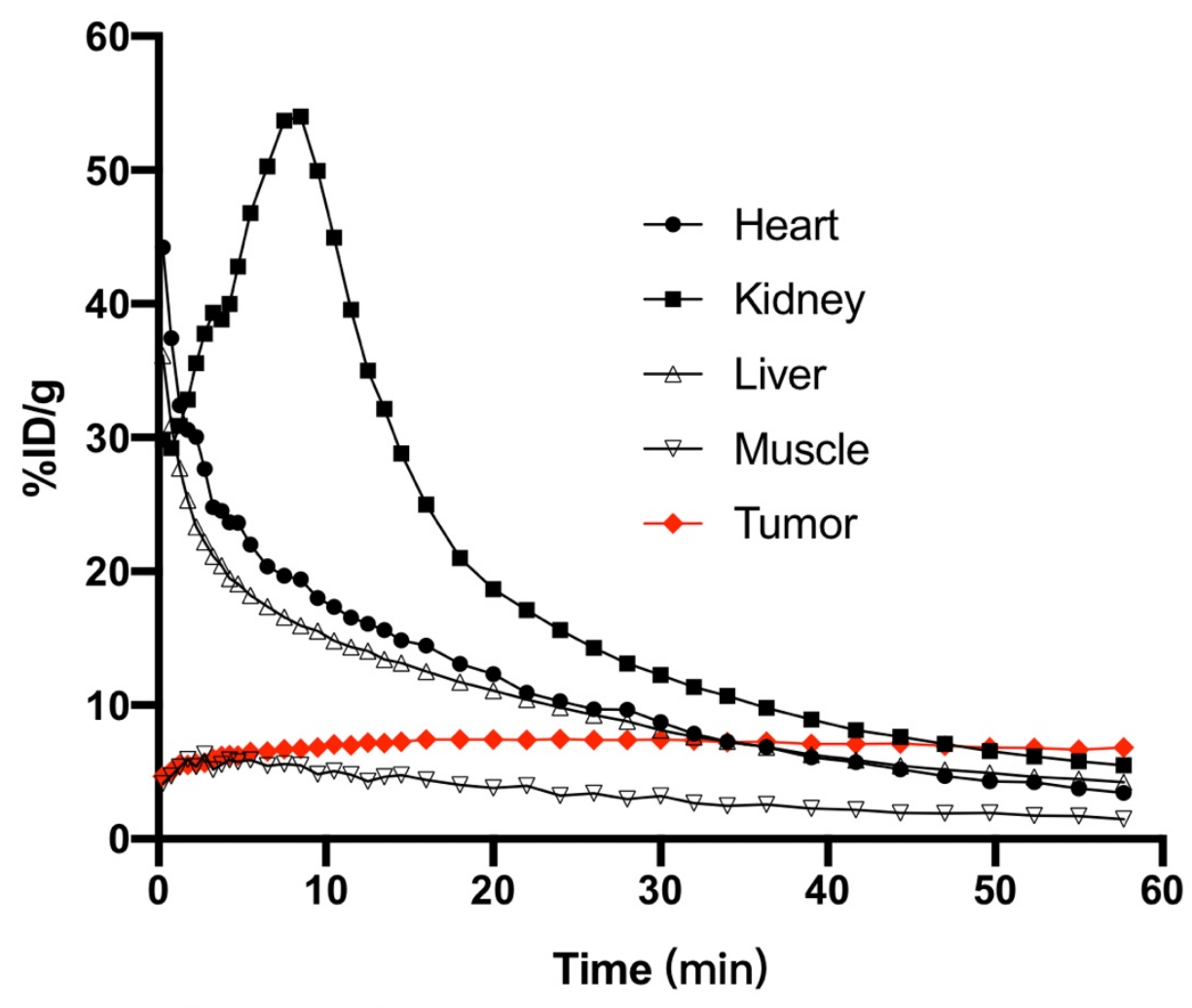

\section{HCC-PDX-2}

Supplemental Figure 6 Dynamic time-activity curves of ${ }^{68} \mathrm{Ga}-\mathrm{DOTA}-2 \mathrm{P}(\mathrm{FAPI})_{2}$ in the heart, kidney, liver, muscle, and tumor in HCC-PDX-2. 


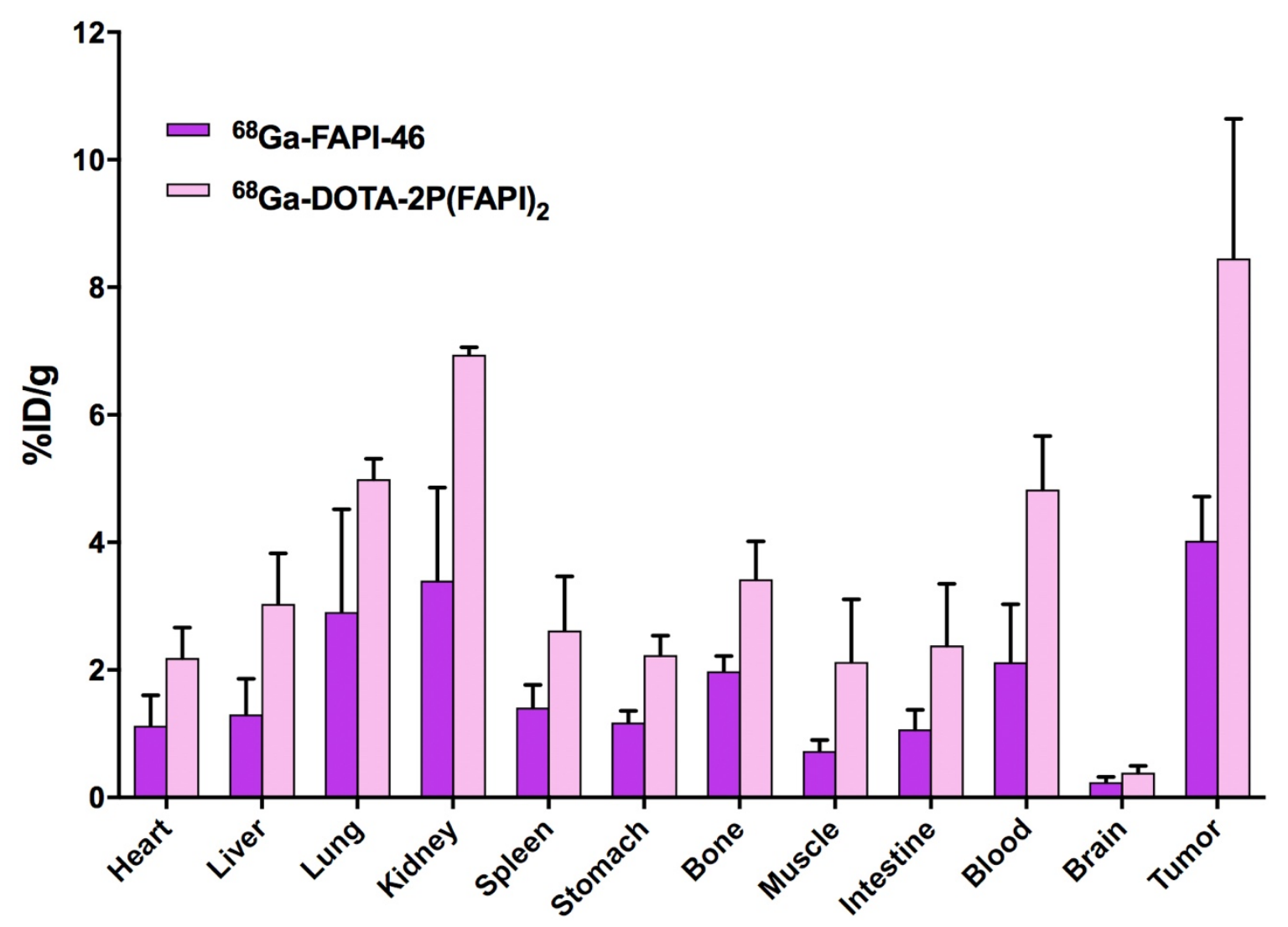

Supplemental Figure 7. Ex-vivo biodistribution of ${ }^{68} \mathrm{Ga}-\mathrm{FAPI}-46$ and ${ }^{68} \mathrm{Ga}-\mathrm{DOTA}-2 \mathrm{P}(\mathrm{FAPI}) 2$ (with the same specific activity) in HCC-PDX-1 at $1 \mathrm{~h}$ post-injection ( $\mathrm{n}=3 /$ group). 


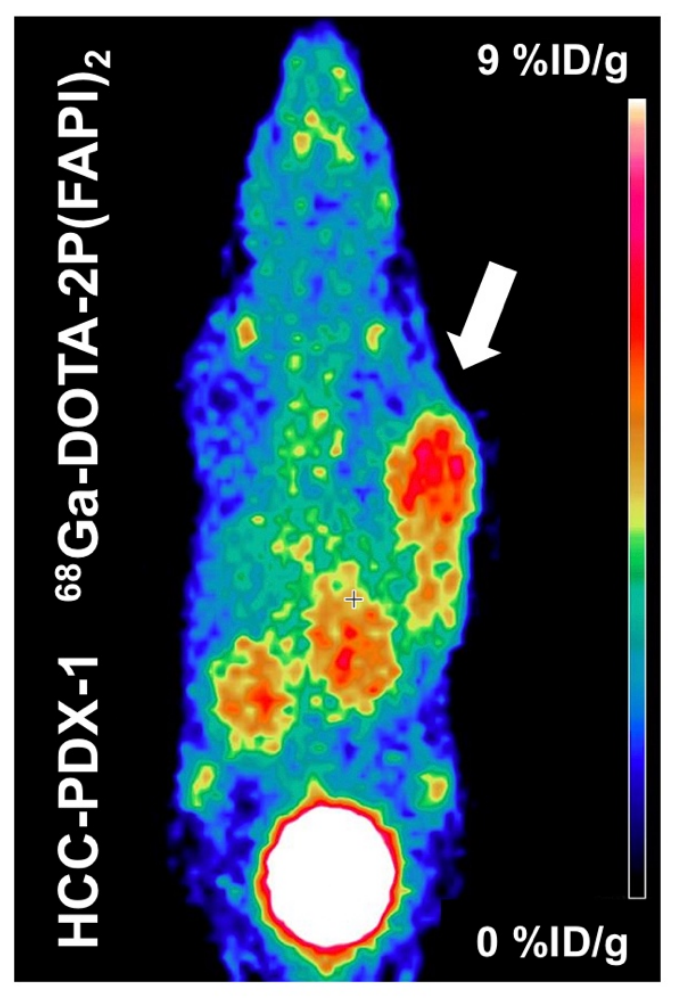

$1 \mathrm{~h}$

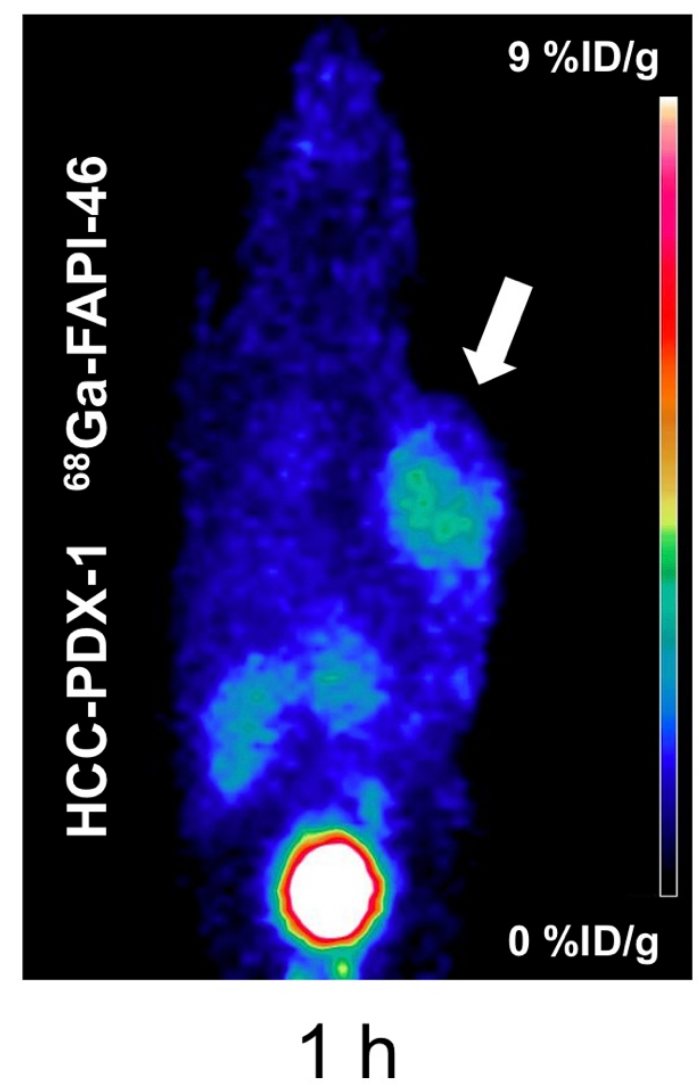

$1 \mathrm{~h}$

Supplemental Figure 8. Representative PET imaging of ${ }^{68} \mathrm{Ga}-\mathrm{DOTA}-2 \mathrm{P}(\mathrm{FAPI})_{2}$ and ${ }^{68} \mathrm{Ga}-\mathrm{FAPI}-46$ (with the same specific activity) in HCC-PDX-1 at $1 \mathrm{~h}$ after administration. 

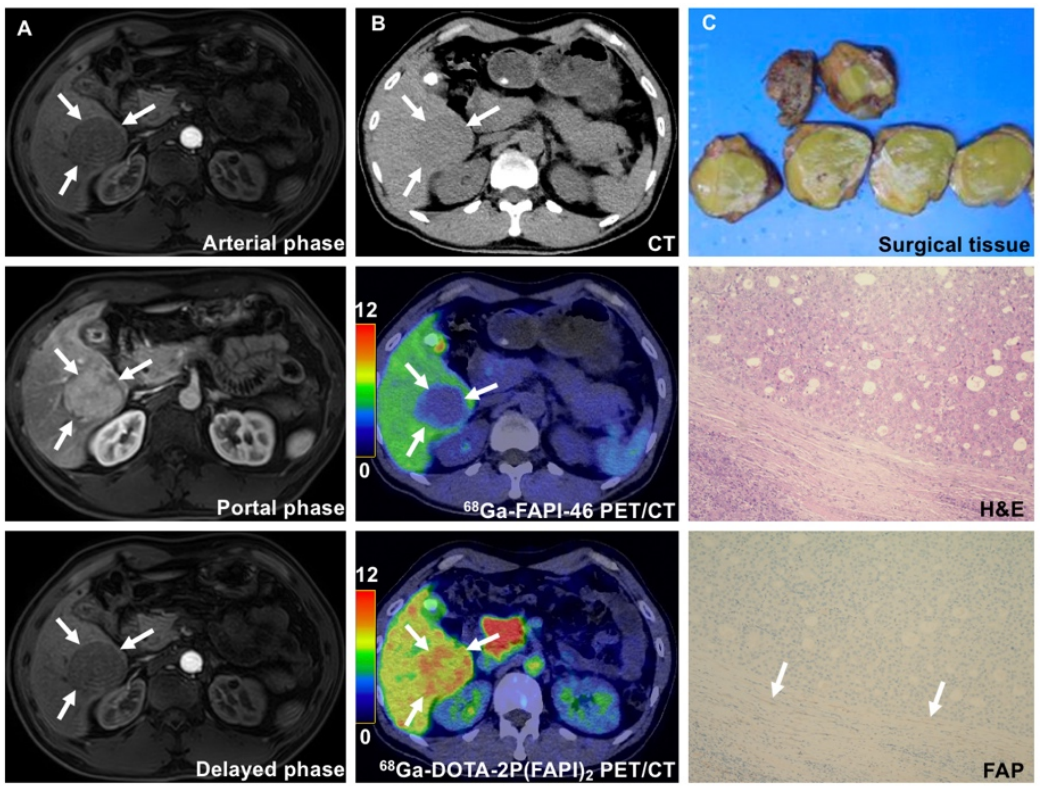

Supplemental Figure $9(A)$. Contrast-enhanced MRI images in a patient with hepatocellular carcinoma (HCC, lesions indicated by arrows); (B). ${ }^{68} \mathrm{Ga}-\mathrm{DOTA}-$ 2P(FAPI)2 PET/CT showed higher tracer uptake than ${ }^{68} \mathrm{Ga}-\mathrm{FAPI}-46$ in the HCC lesion (images acquired at $1 \mathrm{~h}$ post-injection). The increased background FAPI uptake in liver parenchyma was due to liver cirrhosis; (C). Histopathological results after surgery confirmed the diagnosis of HCC (Edmondson-Steiner grading system, grade II), and immunohistochemistry staining showed low FAP expression in the tumor stroma. 

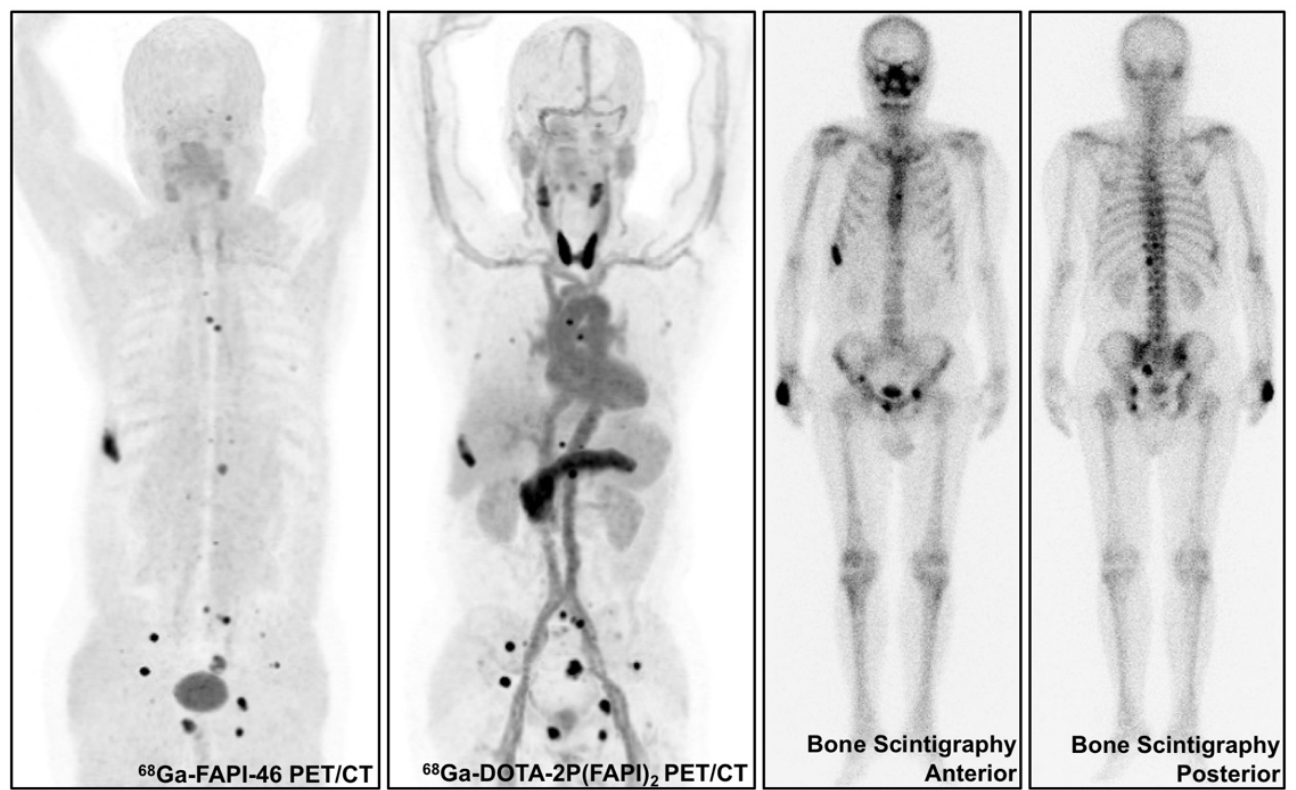

Supplemental Figure 10. ${ }^{68} \mathrm{Ga}-\mathrm{FAPI}-46$ and ${ }^{68} \mathrm{Ga}-\mathrm{DOTA}-2 \mathrm{P}(\mathrm{FAPI})_{2} \mathrm{PET} / \mathrm{CT}$ showed multiple bone metastases in a patient with metastatic nasopharyngeal carcinoma (non-keratinized undifferentiated carcinoma, who presented disease progression after chemoradiotherapy and immunotherapy). The uptake of ${ }^{68} \mathrm{Ga}$ DOTA-2P(FAPI $)_{2}$ was higher than ${ }^{68} \mathrm{Ga}-\mathrm{FAPI}-46$ in most of the bone metastases (images acquired at $1 \mathrm{~h}$ post-injection). The bone metastases were further observed in the radionuclide bone scan. 
Supplemental Table 1: Lesion-by-lesion comparison of ${ }^{68} \mathrm{Ga}-\mathrm{FAPI}-46$ and ${ }^{68} \mathrm{Ga}-$ DOTA-2P(FAPI $)_{2}$ uptake in three cancer patients.

\begin{tabular}{|c|c|c|c|c|c|c|c|c|}
\hline $\begin{array}{l}\text { Patient } \\
\text { No. }\end{array}$ & Age & Sex & Status & $\begin{array}{l}\text { No. of } \\
\text { lesions }\end{array}$ & Site of lesions & $\begin{array}{l}{ }^{68} \mathrm{Ga}-\mathrm{FAPI}-46 \\
\text { SUVmax }\end{array}$ & $\begin{array}{l}{ }^{68} \text { Ga-DOTA- } \\
2 \text { P(FAPI) } \\
\text { SUVmax }\end{array}$ & $P$ \\
\hline \multirow[t]{10}{*}{$\begin{array}{l}\text { Patient1 } \\
\text { (NPC) }\end{array}$} & 71 & Male & Recurrence & $>10$ & Bone 1 & 16.3 & 17.8 & 0.005 \\
\hline & & & & & Bone 2 & 24.7 & 27.5 & \\
\hline & & & & & Bone 3 & 23.4 & 27.4 & \\
\hline & & & & & Bone 4 & 14.4 & 25.1 & \\
\hline & & & & & Bone 5 & 22.0 & 29.8 & \\
\hline & & & & & Bone 6 & 9.8 & 20.8 & \\
\hline & & & & & Bone 7 & 8.1 & 17.2 & \\
\hline & & & & & Bone 8 & 13.3 & 22.1 & \\
\hline & & & & & Bone 9 & 17.4 & 27.6 & \\
\hline & & & & & Bone 10 & 11.6 & 23.3 & \\
\hline \multirow{10}{*}{$\begin{array}{l}\text { Patient } 2 \\
\text { (Thyroid } \\
\text { cancer) }\end{array}$} & 34 & Male & Recurrence & $>10$ & Cervical node 1 & 20.0 & 32.8 & 0.005 \\
\hline & & & & & Cervical node 2 & $1.7^{*}$ & 8.1 & \\
\hline & & & & & Supraclavicular node 1 & 24.0 & 39.0 & \\
\hline & & & & & Supraclavicular node 2 & 12.8 & 24.1 & \\
\hline & & & & & Axillary node 1 & 17.8 & 23.2 & \\
\hline & & & & & Axillary node 2 & 17.7 & 33.2 & \\
\hline & & & & & Axillary node 3 & 16.7 & 28.9 & \\
\hline & & & & & Bone 1 & 11.4 & 26.4 & \\
\hline & & & & & Mediastinal node 1 & 23.4 & 24.6 & \\
\hline & & & & & Hilar node 1 & 11.5 & 18.1 & \\
\hline $\begin{array}{l}\text { Patient } 3 \\
\text { (HCC) }\end{array}$ & 46 & Male & Initial stage & 1 & Primary tumor & 2.7 & 9.8 & NA \\
\hline
\end{tabular}

Note: HCC, hepatocellular carcinoma; NPC, nasopharyngeal carcinoma; No., number; SUVmax, maximum standardized uptake value; ${ }^{*}$, negative in ${ }^{68} \mathrm{Ga}-$ FAPI-46 PET/CT 


\section{References}

1. Chen H, Zhao L, Fu K, et al. Integrin alphavbeta3-targeted radionuclide therapy combined with immune checkpoint blockade immunotherapy synergistically enhances anti-tumor efficacy. Theranostics. 2019;9:7948-7960.

2. Chen H, Pang Y, Wu J, et al. Comparison of [(68) Ga]Ga-D0TA-FAPI-04 and $[(18) \mathrm{F}]$ FDG PET/CT for the diagnosis of primary and metastatic lesions in patients with various types of cancer. Eur $J$ Nucl Med Mol Imaging. 2020. 